\title{
EVALUATING RISK ASSESSMENTS AMONG SEX OFFENDERS: A COMPARATIVE ANALYSIS OF STATIC AND DYNAMIC FACTORS
}

by



Carleton University

Ottawa, Canada 


\begin{abstract}
In two studies, the predictive accuracy and the incremental validity of different dynamic risk assessment measures were examined. In Study 1, the Dynamic Risk Assessment for Offender Re-Entry (DRAOR), which is a measure of dynamic risk and protective factors, was examined with a sample of 203 male adult sexual offenders. The results demonstrated that the DRAOR significantly predicted technical violations, but failed to significantly predict sexual recidivism. Further, the DRAOR made a significant incremental contribution over the Static-99R for predicting technical violations. In Study 2, the Stable-2007 and Acute-2007, which were designed to assess dynamic predictors of sexual recidivism among male adult sexual offenders, were examined with a sample of 207 sex offenders. Results showed that both dynamic measures significantly predicted technical violations, but demonstrated weak predictive accuracy for sexual reoffense. The Stable-2007 and Acute-2007 also added incremental validity to the prediction of technical violations over and above the Static-99R.
\end{abstract}




\section{Table of Contents}

Abstract

ii

List of Tables

.

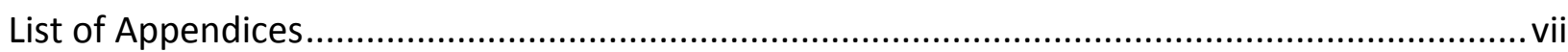

Evaluating Risk Assessments Among Sex Offenders: A Comparative Analysis of Static and













Unique Dynamic Predictors of Sexual Recidivism ....................................................... 15

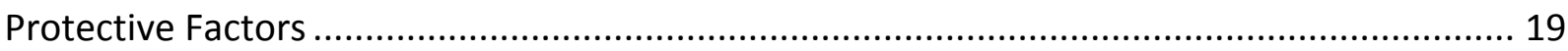



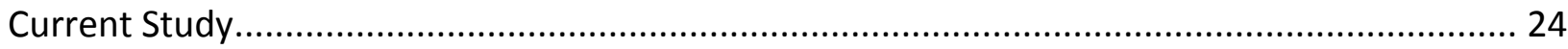

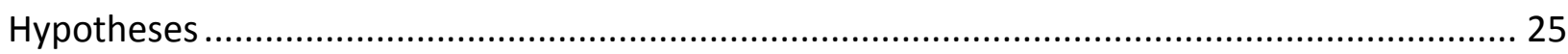





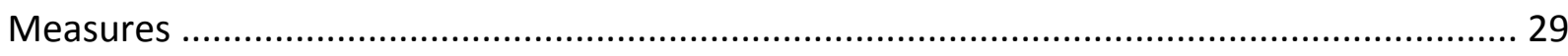








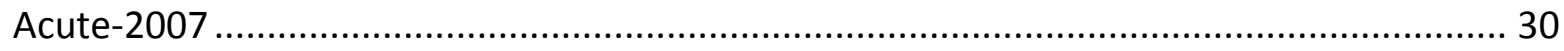

Dynamic Risk Assessment for Offender Re-Entry................................................. 31

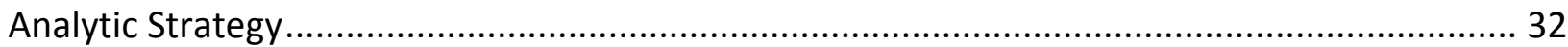

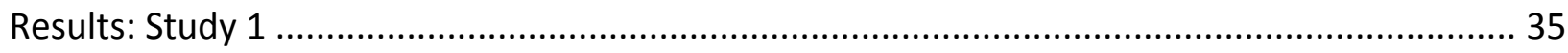

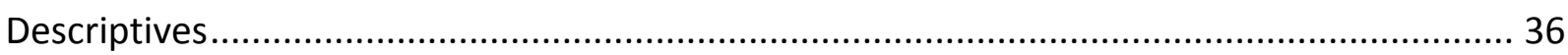

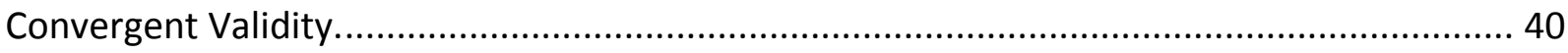

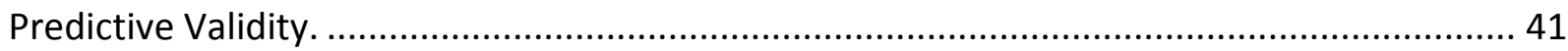

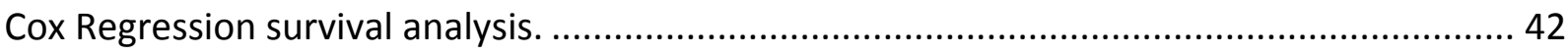

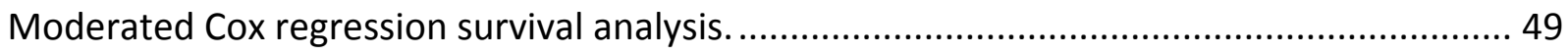

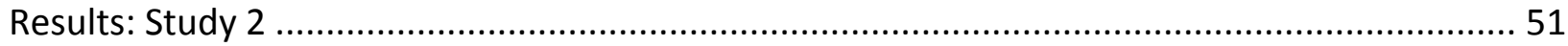

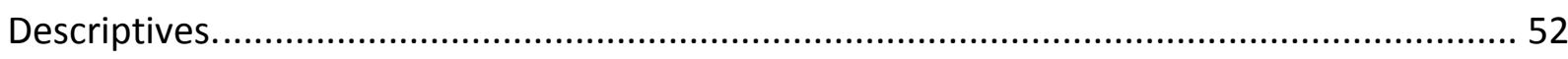

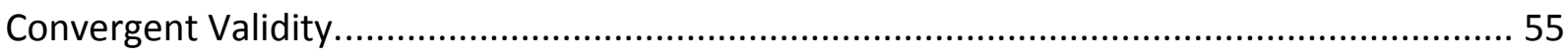



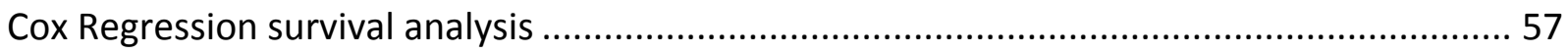

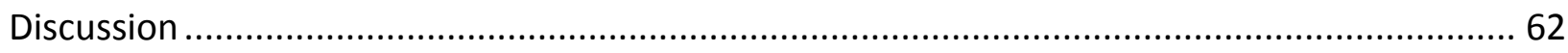

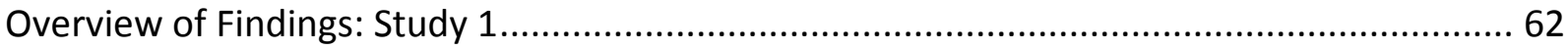

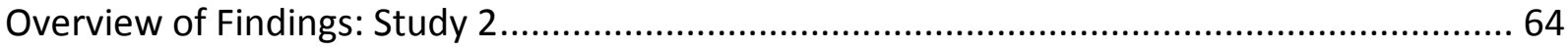

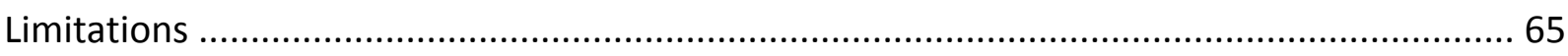

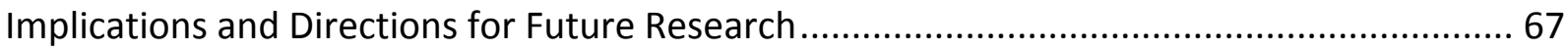

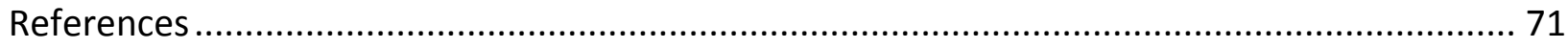




\section{List of Tables}

Table 1 Sample Demographics-Study 1 .27

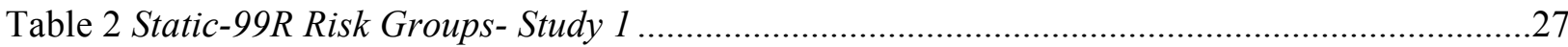

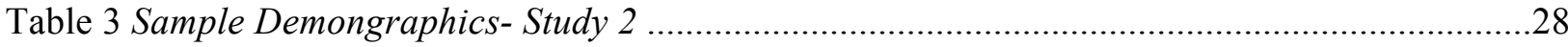

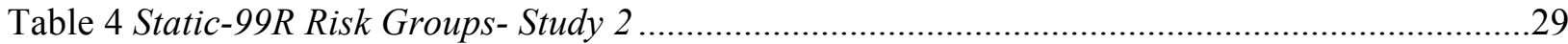

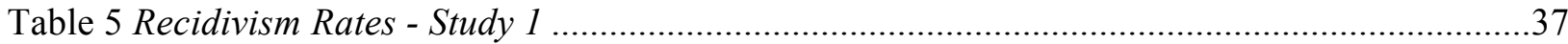

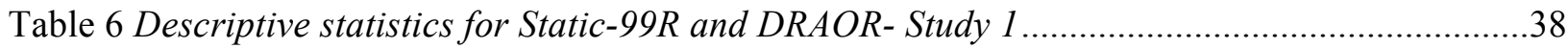

Table 7 Comparisons between Rapists and Child Molesters- Study 1 .............................................38

Table 8 Parole Violations: Comparisons between Recidivists and Non-Recidivists-Study 1 ..............39

Table 9 Sexual Recidivism: Comparisons between Recidivists and Non-Recidivists-Study1 _.............40

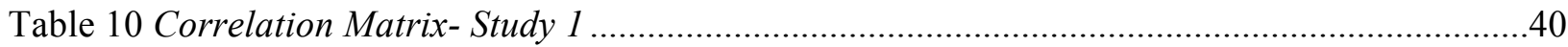



Table 12 Cox Regression Survival Analysis Prediciting Sexual Recidivism: Univariate

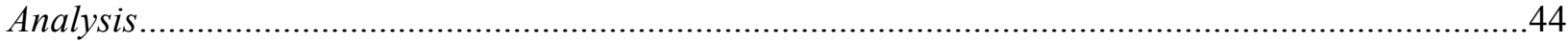

Table 13 Cox Regression Survival Analysis Prediciting Parole Violations: Univariate

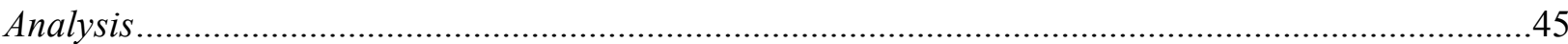

Table 14 Cox Regression Survival Analysis Prediciting Parole Violations: Multivariate

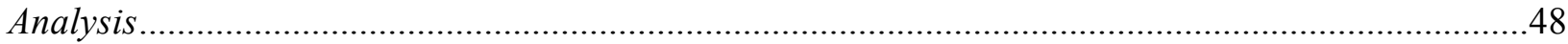

Table 15 Moderated Cox Regression Survival Analysis .................................................................50

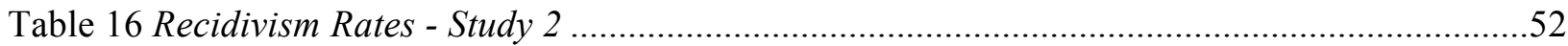

Table 17 Descriptive statistics for Static-99R, Stable-2007, and Acute-2007-Study 2 .....................53

Table 18 Comparisons between Rapists and Child Molesters- Study 2 .........................................53

Table 19 Parole Violations: Comparisons between Recidivists and Non-Recidivists-Study 2 ............54

Table 20 Sexual Recidivism: Comparisons between Recidivists and Non-Recidivists-Study 2 ...........55 


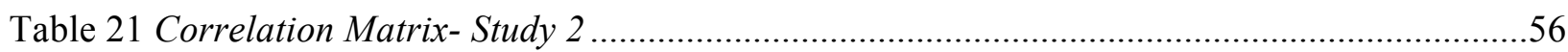

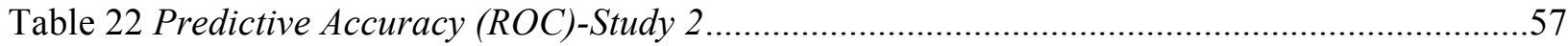

Table 23 Cox Regression Survival Analysis Prediciting Sexual Recidivism: Univariate

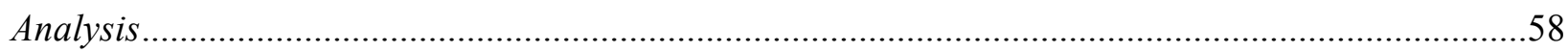

Table 24 Cox Regression Survival Analysis Prediciting Parole Violations: Univariate

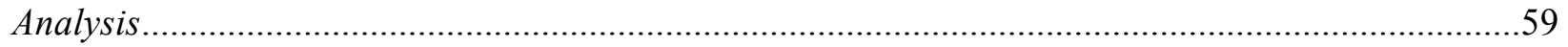

Table 25 Cox Regression Survival Analysis Prediciting Parole Violations: Multivariate

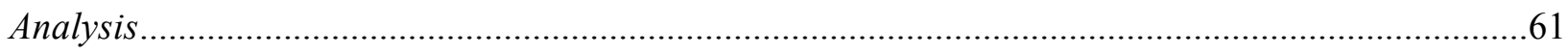




\section{List of Appendices}

Appendix A: Dynamic Risk Assessment for Offender Re-Entry (DRAOR)....79

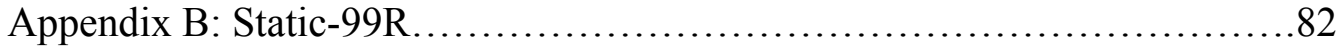

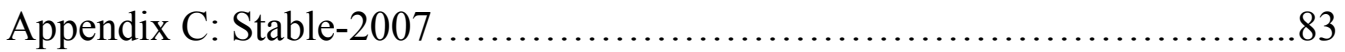

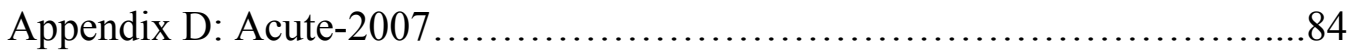


Evaluating Risk Assessments Among Sex Offenders: A Comparative Analysis of Static and Dynamic Factors

The devastating effects of sexual offending are far reaching, causing immeasurable impact on their victims as well as public safety concerns. Consequently, the issue of accurately predicting sexual recidivism has come to the forefront as a matter of criminal justice policy and public safety debates. Risk and need assessments have several important functions and applications within the criminal justice system, such as providing informed decisions about the type and intensity of treatment services within the correctional environment (Andrews \& Bonta, 2010). In addition, once sex offenders are released into the community, the appraisal of risk is able to inform parole and probation officers about the nature and amount of supervision needed in order to reduce the likelihood of recidivism. Therefore, constructing and evaluating the validity of risk assessment tools have become a major priority.

In the last two decades, there has been a proliferation in empirical studies examining different risk assessment approaches; beginning with an emphasis on static, historical variables and moving to an examination and inclusion of dynamic, causal risk factors. Further, focus has slowly been shifting from risk prediction efforts to an emphasis on risk prevention and management (Douglas \& Kropp, 2002; Douglas \& Skeem, 2005). Risk prevention is concerned with the identification of factors that have the potential to reduce and manage risk (Douglas \& Kropp, 2002; Douglas \& Skeem, 2005). Douglas and Kropp (2002) assert "a need for an integrated model of risk assessment and management/treatment, one in which violence prevention strategies flow directly from assessment procedures" (p. 623). In addition, risk management efforts now include dynamic factors, which are changeable, but also increasingly protective factors (Douglas \& Skeem, 2005; Ullrich \& Coid; 2011). Protective factors are 
conceptualized as those factors that mitigate or buffer the effect of risk factors and emphasize strength and resiliency within an individual (Haggard, Gumpert \& Grann, 2001; Ullrich \& Coid, 2011). Therefore, this emerging risk-protective paradigm may help explain unexpected outcomes by examining those offenders deemed high risk but who 'defied the odds' (Haggard et al., 2001; Miller, 2006; Rogers, 2000; Ullrich \& Coid, 2011).

In two studies, the predictive accuracy and the incremental validity of various dynamic risk assessment measures will be examined. In Study 1, the purpose will be to extend earlier work examining risk prediction for sexual reoffending and to determine if it can be improved by using both dynamic risk factors and protective factors. The Dynamic Risk Assessment for Offender Re-Entry (DRAOR; Serin, 2007; Serin, Mailloux, \& Wilson, 2010) is a new body of work that includes empirically informed dynamic and protective factors. This research will examine whether the DRAOR can be usefully applied to sex offenders in order to accurately predict recidivism and whether the DRAOR can incrementally predict sexual and parole failures over and above static risk estimates. In Study 2, the predictive accuracy and incremental validity of the Stable-2007 and Acute-2007, which were designed to assess dynamic predictors of sexual recidivism among adult sex offenders, will be examined to determine if they can add to the prediction of recidivism above what can be predicted by static risk scores.

This study will first review the literature on risk assessment, with a focus on the different types of risk factors, as well as common approaches to conducting applied risk assessment. The unique dynamic predictors of sexual recidivism will also be reviewed, as well as current research examining the role of protective factors in the assessment of risk. Utilizing risk instruments that incorporate both dynamic and protective factors in the process of prediction can help researchers better understand why some offenders reoffend while others do not, despite similar static risk 
ratings. Although there has been substantial progress in this area, there is still a need to further develop and enhance risk assessments with conceptual innovation.

\section{Assessing Risk for Recidivism}

Andrews and Bonta's (2010) seminal work on the Psychology of Criminal Conduct (PCC) has had extensive empirical investigation that has informed the practices for the assessment of risk and the management of offenders. The PCC is truly an interdisciplinary approach, incorporating both a general personality and cognitive social leaning perspective with emphasis on individual variation in personal, interpersonal, and social factors related to criminal behaviour (Andrews \& Bonta, 2010). Under a broad theoretical framework, the PCC includes the risk, need and responsivity (RNR) principles of effective assessment and intervention (Andrews \& Bonta, 2010). The RNR principles developed by Andrews and Bonta (2010) posit that those correctional programs and practices that will have the biggest impact on recidivism rates are those that target higher risk offenders, that focus on their malleable risk factors (i.e. criminogenic needs) and that attend to those factors that influence their ability to successfully complete treatment (i.e. responsivity factors; Andrews \& Bonta, 2010).

A determination of an offender's risk level can be based on static risk factors, which are historical, unchanging variables, such as past criminal behaviour, and they have been conceptualized as risk markers for underlying psychological dispositions (i.e. dynamic variables; Andrews \& Bonta, 2010; Douglas \& Skeem, 2004; Beech \& Ward, 2004). However, static factors are not amenable to change through direct intervention efforts and do not provide direction on what factors to target in treatment in order to reduce risk (Douglas \& Kropp, 2002; Douglas \& Skeem, 2005; Hanson, Morton, \& Harris, 2003). Thus, static risk factors offer singlepoint estimations of risk and cannot determine if an offenders risk has increased or decreased 
over-time (Douglas \& Kropp, 2002; Douglas \& Skeem, 2005). Further, risk status highlights static factors and can only be used to examine inter-individual variability in risk (Douglas \& Skeem, 2005). Although static factors are good for long-term predictive ability, they offer little guidance in differentiating which offenders have benefitted from treatment and they are unable to inform criminal justice professionals when an offender is likely to reoffend (Douglas \& Skeem, 2005).

Dynamic risk factors are those factors that are causally related to criminal behaviour and are amenable to change through planned intervention strategies (Andrews \& Bonta, 2010). Specifically, causal dynamic risk factors must precede the outcome of interest (e.g., recidivism), with change on these factors related to differential outcomes (Kraemer et al., 1997). Consequently, dynamic risk factors are important in identifying treatment targets, and aiding in treatment planning and delivery. Further, risk state emphasizes dynamic risk factors that can be used in evaluating intra-individual change pre and post treatment and while on community supervision (Douglas \& Skeem, 2004; Hanson \& Morton-Bourgon, 2004; Seto \& Fernandez, 2011). Therefore, accurately assessing offenders' dynamic risks has important ramifications for treatment success and supervision.

Dynamic risk factors can be further divided into acute and stable risk factors. Stable dynamic risk factors are slowly changing, such as over months or years and typically reflect enduring traits, such as criminal attitudes and negative social influences (Beech, Fisher, \& Thornton, 2003; Craig, Thornton, Beech \& Browne, 2007; Hanson \& Harris, 2000, 2001; Hanson et al., 2007; Hanson, Morton \& Harris, 2003). Stable factors therefore reflect treatment targets and underlie intra-individual change. In contrast, acute risk factors are highly transient, which can change over days or even hours, such as negative mood and victim access (Hanson \& 
Harris, 2000, 2001; Hanson et al., 2007). They indicate the probability of short-term change and can inform criminal justice professionals regarding risk management strategies in terms of when an offender is most likely to reoffend (Hanson \& Harris, 2000, 2001; Hanson et al., 2007). Stable and acute risk factors do not operate in isolation. Instead, the interplay between these factors can be explained by the fact that even those offenders assessed as high-risk may see fluctuations in risk level based on the absence or presence of certain contextual factors (Beech et al., 2003; Kroner et al., 2011). Therefore, examining acute risk factors and incorporating them into risk assessment tools is crucial for community supervision as they potentially signal the timing of new offences.

\section{Approaches to Risk Assessment}

Depending on the type of offender, the goal of risk assessment (i.e. predicting general, violent or sexual recidivism), and the collateral data sources available, there are various approaches and instruments available. However, the ideal measure, according to Hanson and Morton-Bourgon (2009) should have the largest relationship to recidivism, smallest confidence intervals and least variability across samples. More importantly, risk assessments should be grounded in a strong theoretical foundation in order to understand why certain risk factors are causally linked to recidivism (Andrews et al., 2006; Craig et al., 2007; Hanson \& MortonBourgon, 2007). Thus, the inclusion of items within any risk assessment should incorporate factors that are theoretically related to the outcome of interest, as these assessment approaches can aid in scale development and strategies for intervention (Kroner, Mills \& Reddon, 2005). For instance, Kroner et al. (2005) compared psychometrically established risk scales to randomly generated instruments. Although the items were derived from established scales, the construction of these scales was random (Kroner et al., 2005). Results indicated that the established scales 
were no more accurate than the randomly generated scales, demonstrating the need for theoretically derived predictors in order to reduce criminal behaviour (Hanson \& MortonBourgon, 2007; Kroner et al., 2005).

Bonta (1996) described three generations of risk assessment, beginning with unstructured clinical judgment. With this first-generation of risk scales, the estimation of risk is based on the assessors own experience and their knowledge about what constitutes important risk factors (Hanson \& Morton-Bourgon, 2009; Harris \& Hanson, 2010). This approach is highly subjective, resulting in low inter-rater reliability and low predictive accuracy. The obvious limitations of first generation risk assessment tools spurred the development of a standardized, objective approach to risk assessment. Actuarial risk assessments select and weigh items based on their empirical relationship to recidivism, often derived from meta-analyses (Barbaree, Langton, \& Peacock, 2006; Harris \& Hanson, 2010). The items included are largely static, historical variables and provide explicit methods for combining the risk factors, which are linked to probability estimates of recidivism (Hanson \& Morton-Bourgon, 2009; Harris \& Hanson, 2010). However, actuarial tools are largely statistical and atheoretical in nature and do not provide reasons as to why those factors are linked to criminal behaviour (Andrews \& Bonta, 2010; Andrews et al., 2006; Craig et al., 2007). Although not included in Bonta's generational descriptions, structured professional judgments (SPJ) can be thought of as a hybrid of first and second-generation risk assessments. SPJ include explicit guidelines on which factors to consider, but the combination of those factors, the overall evaluation of risk, and cut points for risk categories are left up to the professional judgement of the assessor (Andrews et al., 2006). Although decisions are made at the individual level, there is still a higher degree of subjectivity than actuarial risk assessments. 
Third-generation assessments emphasize criminogenic factors and core processes that lead to the development and chronicity of criminal behaviour (Andrews et al., 2006; Bonta, 1996). Ostensibly, they are based on empirically validated causal dynamic risk factors capable of guiding the development of prevention-based programs, while also capable of measuring change (Andrews et al., 2006; Bonta, 1996). Dynamic measures are two-pronged: they provide predictive utility, but also have the advantage of offering risk prevention and management services for individual cases.

In contrast to Bonta's (1996) generational descriptions, Hanson and Morton-Bourgon (2009) examined a different classification of risk assessment methods. Based largely on Meehl's (1954) definition of actuarial approaches, their study examined five different approaches to risk assessments. Meehl's criteria state that actuarial scales have an explicit method for combining items into an overall score and those scores are linked to probability estimates (i.e. expected recidivism rates; Hanson \& Morton-Bourgon, 2009). The first category examined was empirical acutarial, which includes specific rules for combing empirically derived items into an overall score, where those scores are linked to expected recidivism rates (Hanson \& Morton-Bourgon, 2009). Mechanical scales, which are largely based on theory or literature reviews, have rules for combining the items, but these overall scores are not linked to probability estimates (Hanson \& Morton-Bourgon, 2009). Adjusted actuarial allows the evaluator to consider external factors not specified in advance and may override the obtained rating from the actuarial or mechanical approach (Hanson \& Morton-Bourgon, 2009). The remaining two categories included structured professional judgement and unstructured clinical judgement.

The results of Hanson and Morton-Bourgon's (2009) meta-analysis found that for all three outcomes examined (i.e. sexual, violent or any recidivism) actuarial and mechanical scales 
developed to predict sexual recidivism demonstrated greater predictive accuracy compared to unstructured clinical judgment. Further, actuarial and mechanical scales designed to predict sexual recidivism demonstrated similar predictive accuracy for predicting sexual recidivism, but differences in predictive accuracy increased when predicting violent or any recidivism (Hanson \& Morton-Bourgon, 2009). In addition, measures designed for specific outcomes (i.e. sexual, violent or any recidivism) generally demonstrated greater predictive accuracy for that outcome. Actuarial adjusted demonstrated decreased predictive accuracy over pure actuarial measures, as it was suggested that the clinical override option was added 'noise' (Hanson \& Morton-Bourgon, 2009).

A prevalent criticism with actuarial approaches is the extent to which the results can be applied at the individual level (Beech et al., 2003; Cooke \& Michie, 2010; Craig \& Beech, 2009; Hart \& Cooke, 2013; Hart, Michie \& Cooke, 2007). That is, since the inclusion of the items is based on group-level data, the applicability to individual offenders is a concern (Beech et al., 2003; Cooke \& Michie, 2010; Craig \& Beech, 2009; Hart \& Cooke, 2013; Hart et al., 2007). Referred to as the statistical fallacy effect (Craig \& Beech, 2009), applying nomothetically based methods to idiographic assessments can reduce the predictive power of a scale. For instance, some studies (Hart \& Cooke, 2013; Hart et al., 2007), have reported large margins of error and increased imprecision at the individual level, concluding that actuarial instruments cannot be used to estimate specific recidivism probabilities at the individual level. However, there still remains considerable debate whether applying recidivism estimates derived from group-level data to single cases will actually reduce the predictive accuracy of an instrument (Hanson \& Howard, 2010; Skeem \& Monaham, 2011). Proponents of actuarial risk assessment instruments argue that the confidence intervals derived from individual cases should not be used to determine 
the predictive accuracy of risk scales (Hanson \& Howard, 2010; Skeem \& Monaham, 2011). Instead, examining the predictive accuracy of a risk assessment instrument should be considered in light of other quality indicators, such as the ability to differentiate between recidivists and non-recidivists, the causal relationship between risk factors and the outcome of interest, and the accuracy and reliability of the risk assessment instrument in identifying risk factors (Hanson \& Howard, 2010; Harris \& Rice, 2007).

\section{Assessing Change}

Risk assessment instruments should not only focus on risk prediction, but also on the prevention and reduction of risk (Douglas \& Kropp, 2002; Douglas \& Skeem, 2004; Olver, Wong, Nicholaichuk \& Gordon, 2007). In order to accomplish this task, risk assessment tools must target causal dynamic risk factors (Kraemer et al., 1997) that are directly related to criminal behaviour and amenable to change through direct intervention (Douglas \& Kropp, 2002; Douglas \& Skeem, 2004; Beech et al., 2003). By regularly measuring change within an individual, evaluators can determine their rate of change and whether treatment intensity and their level of community supervision should be modified to match their current risk state (Douglas \& Kropp, 2002; Douglas \& Skeem, 2004). Thus, accurately assessing an offender's risk over time has important implications for decision-making at all levels of intervention. Dynamic risk factors must not only be able to change, but there should also be subsequent changes in recidivism risk, with incremental contributions to the predictive accuracy of recidivism (Craig et al., 2003; Hanson \& Harris, 2000, 2001; Hanson \& Morton-Bourgon, 2004, 2005, 2009). For instance, dynamic items have been found to increase predictive accuracy beyond level achieved by static items (Beech, Friendship, Erikson, \& Hanson, 2002), and they are also able to differentiate between recidivists and non-recidivists (Hanson \& Harris, 2000). 
Although there is a substantive body of literature demonstrating the significant relationship between static estimates and recidivism risk, including for sex offenders, there is a lack of research consistently and reliably demonstrating that changes in dynamic risk factors are actually related to differential outcomes (Douglas \& Skeem, 2005; Hanson \& Morton-Bourgon, 2004, 2005, 2009). Further, there is a paucity of empirical studies establishing whether dynamic factors are equal to, better than or incrementally greater than static estimates (Douglas \& Skeem, 2005; Hanson \& Morton-Bourgon, 2004, 2005, 2009). Further, the extant literature on the dynamic predictors of sexual recidivism remains sparse, with few empirical studies looking at changes in risk with sexual offenders. Those studies that do look at change have suffered methodological limitations, such as small sample sizes, retrospective design studies (Hanson \& Harris, 2000), and single-point evaluations (Beech et al., 2002). Evaluations of dynamic variables should be conducted on at least two occasions, and employ a prospective, longitudinal design, in order to evaluate whether changes on these variables are related to change in risk for recidivism (Brown et al., 2009; Douglas \& Skeem, 2005; Kraemer et al., 1997).

Brown et al., (2009) designed a three-wave prospective study with general offenders that examined changes in dynamic risk factors, such as employment problems, negative affect, social support and substance abuse, to determine if the dynamic measures changed for offenders that did not recidivate. A series of within-subject repeated measures was used to determine if the dynamic variables actually changed during the assessment phase and whether those changes predicted recidivism (Brown et al., 2009). The dynamic variables were measured on three different occasions: 45 days prior to release, one month post-release and 3 months post-release (Brown et al., 2009). The results indicated that the majority of the dynamic items demonstrated significant within-subject change in the expected direction, where the changes significantly 
predicted recidivism (Brown et al., 2009). Therefore, the majority of the dynamic items in this study can truly be regarded as dynamic since the items demonstrated intra-individual change, with variation in those variables related to an increase in predictive accuracy.

With respect to examining change with a sex offender population, Olver et al., (2007) examined the Violence Risk Scale-Sexual Offender version (VRS-SO), which is an actuarial instrument with 7 static and 17 dynamic items. The VRS-SO was developed to integrate sex offender risk assessment strategies and treatment planning, (including assessment of change), into one instrument (Olver et al., 2007). The dynamic items were assessed pre and post treatment to determine if changes in the VRS-SO dynamic items were related to changes in sexual recidivism (Olver et al., 2007). The results demonstrated that positive changes in the dynamic items indicated subsequent reductions in sexual recidivism (Olver et al., 2007). Concomitantly, the post-treatment dynamic items made significant incremental contributions when pre-treatment scores on the static and dynamic items were controlled (Olver et al., 2007).

In a more recent study, Wakeling, Beech and Freemantle (2013) examined the relationship between treatment gain and recidivism with a sample of 3, 773 sex offenders, all of whom completed treatment between 1996 and 2006 (Wakeling et al., 2013). This study sought to determine if treatment gain pre and post treatment (i.e. change) within each of the dynamic risk factors was associated with reduced recidivism (Wakeling et al., 2013). These dynamic factors included sexual interests, pro-offending attitudes, socio-affective problems and self-regulation problems. Results demonstrated that those offenders requiring more change in the sexual interests, socio-affective problems and self-regulation had greater recidivism rates than offenders who did not require further change in these areas (Wakeling et al., 2013). In addition, the overall change rating was related with reduced recidivism (Wakeling et al., 2013). This study is 
consistent with previous research demonstrating that measures of treatment gain significantly predicted reduced sexual recidivism rates (Barnett, Wakelling, Mandeville-Norden \& Rakestrow, 2013; Beggs \& Grace, 2011). These studies offer promising results regarding the relationship between treatment changes on dynamic variables and reductions in recidivism rates.

\section{Evidence of Efficacy}

The assessment of predictive estimates must also be examined, such as assessing scale construction, type of outcome being predicted, length of follow-up time and the training and experience of the evaluators (Barbaree, Seto, Langton, \& Peacock, 2001; Hanson \& Bussier, 1998; Hanson \& Morton-Bourgon, 2004, 2005, 2007, 2009; Hanson, Morton \& Harris, 2003; Harris \& Hanson, 2010). With regard to outcome criteria, it should be expected that the accuracy should be higher for the outcome for which they were designed (Hanson \& Morton-Bourgon, 2004, 2007, 2009). However, risk assessment tools developed for predicting general and violent recidivism are also effective in predicting sexual recidivism among sexual offenders (Hanson \& Morton-Bourgon, 2004). For instance, the Statistical Information on Recidivism-Revised1 (SIRR1) scale was found to significantly predict sexual recidivism among sex offenders with the same degree of accuracy as it did among violent and general offenders (Hanson \& MortonBourgon, 2004). This is not surprising given that antisocial orientation is well represented in risk assessments for general and violent recidivism and is a strong risk indicator for sexual recidivism, for some types of sex offenders.

Various methodological issues influence risk prediction research. Foremost among them is base rates. Low base rates pose problems for an instrument's predictive accuracy as they can hinder the ability to detect statistically significant relationships (Craig \& Beech, 2009; Hanson, Morton, \& Harris, 2003). Base rates can vary based on offender types, length of follow-up, as 
well as the type and definition of the outcome criterion being predicted (Hanson, et al., 2003).

With regard to offender type, sex offenders typically have low-base rates, with approximately a $14 \%$ sexual recidivism rate within the first five years of release (Hanson et al., 2003). This number incrementally increases with longer follow-up periods, but only reaches about $27 \%$ at 20 years (Hanson et al., 2003). Despite the purported low rate of sexual recidivism among sex offenders, it may be an underestimation as many crimes go unreported (Craig \& Beech, 2009; Hanson et al., 2003).

\section{Application to Sex Offenders}

When examining predictors of sexual recidivism, there is a need to consider whether there is a substantial difference between predictors of sexual and non-sexual recidivism. Although it has been argued (Hanson \& Bussier, 1998) that specific processes may be contributing to sexual offending, there are similar variables that predict both sexual and nonsexual recidivism. While deviant sexual interests are one of the strongest predictors of sexual recidivism, not all sex offenders display sexual deviancy and this factor cannot account for all the variance in rates of sexual recidivism. Instead, factors related to general criminality also predict sexual recidivism among sex offenders, with considerable overlap in antisocial attitudes and criminal associates (Hanson \& Morton-Bourgon, 2004, 2005; Serin \& Mailloux, 2003). Concomitantly, criminal lifestyle characteristics, such as impulsivity and substance abuse, have consistently been found to be strong predictors of violent, sexual, and general recidivism (Gendreau et al., 1996; Hanson \& Bussier, 1998; Hanson and Morton-Bourgon, 2004, 2005). Further, non-sexual and sexual offenders have many problems in childhood, engage in interpersonal violence and have a history of antisocial behaviour as juveniles (Hanson and Morton-Bourgon, 2004, 2005). 
Although there are certain characteristics common among sex offenders and associated with the etiology of sex offending, these risk factors are different from factors that are related to the persistence of sexual offending (Hanson \& Bussier, 1998; Hanson and Morton-Bourgon, 2004, 2005). Some of these antecedent factors include adverse childhood environment, general psychological problems and clinical presentation variables (Hanson \& Bussier, 1998; Hanson \& Morton-Bourgon, 2004, 2005). Adverse family environment, such as a history of physical and sexual abuse, has played a significant role in the etiology of sex offending. Also, being in a family where violence is the norm for solving problems or in an environment where early sexual abuse has occurred may put those individuals at risk for adopting such strategies (Beech \& Ward, 2004; Marshall, 1989). Although developmental adversity may result in a vulnerability to sexually abuse, it is not related to a chronic propensity to sexually offend (Hanson \& Bussiere, 1998; Hanson \& Morton-Bourgon 2005, 2009). For instance, in Hanson \& Bussier's metaanalysis (1998) general family problems and being sexually abused as a child did not have a significant relationship with sexual recidivism $(r=.08$ and $r=-.01$, respectively). Therefore, these developmental factors may be important to the etiology of sex offending but they are not significant predictors of persistent sexual offending and are therefore, not represented in risk assessment instruments for sex offenders (Hanson \& Bussier, 1998; Hanson \& Morton-Bourgon, 2004, 2005).

In the extant literature, there is a general agreement that general psychological problems, such as anxiety, depression, and personal distress, are not predictive of long-term sexual, violent or general recidivism (Gendreau et al., 1996; Hanson \& Bussier, 1998; Hanson \& MortonBourgon, 2004, 2009; Hanson et al., 2007). However, it has been argued that subjective distress is a transient state that may instead be a precursor to sexual behaviours by triggering sexual 
fantasies (Hanson \& Bussier, 1998). That is, it may be that when coping with distress, depression or loneliness, sex offenders learn to abate distress through sexual fantasies and masturbation, which in turn may place them at an increased risk to recidivate. (McKibben, Proulx, \& Lusignan, 1994; Proulx, McKibben and Lusignan, 1996). Further, clinical presentation variables such as low victim empathy, denial, and minimization, have also been shown to be poor predictors of sexual recidivism (Hanson \& Bussier, 1998; Hanson \& Morton-Bourgon, 2004).

\section{Unique Dynamic Predictors of Sexual Recidivism}

Although the empirical literature examining static risk factors for sex offenders is highly developed and well replicated, research examining the significance of dynamic risk factors for sex offenders is still emerging. Since certain subgroups of offenders have distinctive dynamic risk factors, many of the ubiquitous risk scales designated for sex offenders contain unique dynamic predictors of sexual offending, such as deviant sexual interests, sexual preoccupation and sexualized coping. Further, previous research has also demonstrated that when psychopathy and sexual deviance are both present, the sexual failure rate is much greater (Harris \& Rice, 2003; Harris et al., 2003; Rice \& Harris, 1997; Serin et al., 2001).

\section{Sexual Attitudes}

Much of the current research examines the content of cognitions (i.e. what offenders are thinking), but research is moving toward examining sex offenders' cognitive processes (i.e. how they think; Gannon, 2009; Johnston \& Ward, 1996; Milner \& Webster, 2005). Antisocial cognitions can be explicated by social cognitive theory. Broadly, social cognitive theory examines cognitive processes such as the acquisition, representation and retrieval of information,

in order to understand social behaviour (Johnston \& Ward, 1996; Gannon, 2009). Specifically, three types of cognitive variables are highlighted: cognitive structures (schemas); operations 
(information processing); and products (self-statements and attributions; Johnston \& Ward, 1996). Schemas are pre-existing belief systems that affect what social cues an individual attends to and shape social experiences by relying on these pre-existing belief systems to understand social situations (Gannon, 2009; Hanson \& Harris, 2000; Johnston \& Ward, 1996). Thus, schemas are cognitive structures for processing information, such that deviant schemas can bias the information processed in a way that makes sex offending more likely (i.e. justifiable by the perpetrator; Johnston \& Ward, 1996; Gannon, 2009). Consequently, the enactment and maintenance of deviant sexual schemas are dependent on the frequency of rehearsal, commonly occurring circumstances, social acceptability and congruency with the offender's personality and values (Hanson \& Harris, 2000).

Schemas are also important in explaining cognitive distortions and offense-supportive beliefs (Gannon, 2009; Serin \& Mailloux, 2003). Cognitive distortions are maladaptive beliefs and distorted thought patterns that may be important in the development and maintenance of sexual offending (Milner \& Webster, 2005). Thus, schemas provide a framework for justifications and attitudes tolerant of sexual offending (Milner \& Webster, 2005; Proulx et al., 1996). However, the predictive ability of sexual attitudes has been mixed. For instance, Hanson \& MortonBourgon (2004), found the general category of attitudes tolerant of sexual offending was significantly related to sexual recidivism, but the effects were not significant for child molester attitudes (i.e. attitudes tolerant of adult-child sex), and low sex knowledge. Conversely, Hanson et al., (2007) did not find a significant relationship between deviant sexual attitudes and sexual recidivism, attributing this lack of significance to possible measurement issues. 


\section{Intimacy Deficits}

The stability of relationships as well as relationship difficulties have been regarded as important factors in the assessment of general, violent and sexual offenders. Intimacy is a way of relating to other people, where deficiencies in this area are marked by a lack of meaningful intimate relationships coupled with little satisfaction (Beech et al., 2003; Hanson \& MortonBourgon, 2004). In addition, early childhood sexual and physical abuse appears instrumental in the development of intimacy deficits and sexual offending. Hanson and Morton-Bourgon (2004) found that certain intimacy deficit indicators, such as emotional identification with children $(d=$ $.42)$ and conflicts with intimate partners $(d=.36)$ were predictive of sexual recidivism. However, neither emotional loneliness $(d=.03)$ or low social skills $(d=-.07)$ were predictive of sexual recidivism; instead they are regarded as common factors among sex offenders (Hanson \& Morton-Bourgon, 2004, 2005).

In a retrospective, matched group design, comparing recidivists $(n=208)$ and nonrecidivists ( $n=201)$ while on community supervision, Hanson and Harris, (2000) identified several significant dynamic risk factors that were able to differentiate between the two groups of offenders. Those offenders that reoffended tended to have poor social supports, attitudes tolerant of sexual assault, antisocial lifestyles, poor self-management strategies and difficulties in cooperating with supervision (Hanson \& Harris, 2000). Further, recidivists showed increased anger and distress just before offending (Hanson \& Harris, 2000). In an attempt to examine how well the dynamic risk factors identified from Hanson and Harris (2000) could be integrated into a structured risk assessment tool for sexual offenders, Hanson and Harris (2001) constructed the Sex Offender Need Assessment Rating (SONAR). The SONAR stable dynamic items included intimacy deficits, negative social influences, and attitudes tolerant of sexual offending, sexual 
self-regulation and general self-regulation (Hanson \& Harris, 2001). The acute items included substance abuse, negative mood, anger, and victim access (Hanson \& Harris, 2001). The results demonstrated a moderate ability to differentiate between recidivists and non-recidivists.

However, this study has been criticised because the SONAR items were derived from retrospective file reviews, resulting in recall bias from the supervision officers (Harris \& Hanson, 2010).

Due to the limitations of the SONAR study, Hanson et al., (2007) developed a prospective research design that examined changes in both acute and stable risk factors for new sex offenders starting a period of community supervision. The dynamic supervision project was a large-scale study, involving 997 sex offenders across 16 jurisdictions, with 156 parole and probation officers completing static, acute and stable risk assessments (Hanson et al., 2007). Specifically, they collected static assessments upon intake, stable items every six months and acute factors at every offender contact, all of which was collected for a period of three years (Hanson et al., 2007). The stable risk factors were assessed using the Stable-2000, which was developed for this study. The items on the Stable-2000 were derived from previous research and established risk tools such as the SONAR, (Hanson \& Harris, 2001), The Sex Offender Treatment Evaluation Project (STEP; Beech, 1998), and the Structured Risk Assessment model (SRA; Thornton, 2002). The SONAR, STEP and SRA dynamic items all emphasized the importance of deviant sexual interests, prooffending attitudes and intimacy deficits (Beech, 1998; Beech et al., 2003; Thornton, 2002). The Acute-2000 items were derived from previous research highlighting the importance of immediate precursors to sexual reoffending, such as victim access, rejection of supervision and shifts in moods (Hanson et al., 2007). 
The results of this study demonstrated that both the stable and acute items significantly contributed to the prediction of recidivism above that provided by the Static-99 (Hanson et al., 2007). However, changes on these dynamic risk factors were not related to changes in recidivism risk (Hanson et al., 2007). In fact, offenders changed little on the stable factors between evaluations (Hanson et al., 2007). Interestingly, when the acute ratings were aggregated over six months, they were better at predicting recidivism as opposed to the most proximal evaluation, indicating the acute variables may also have been measuring stable risk factors (Hanson et al., 2007; Harris \& Hanson, 2010). Consequently, better considerations for summarizing acute findings such as evaluating how often an offender has displayed similar behaviour over a period of time may prove more effective in predicting recidivism (Hanson et al., 2007; Harris \& Hanson, 2010). That is, the frequency of collecting information on acute variables, such as weekly or even daily, as opposed to monthly, may reveal truly acute factors (Hanson et al., 2007; Harris \& Hanson, 2010). The results of this project also demonstrated that 10 of the original Stable-2000 items significantly predicted recidivism and were retained in the Stable-2007 (Hanson et al., 2007). The three attitude items (sexual entitlement, attitudes tolerant of rape and attitudes tolerant of adult-child sex) were not related to recidivism and were not included in the Stable-2007. In sum, the Stable-2007 and Acute-2007 demonstrated greater predictive validity than the Stable-2000 and Acute-2000, while also providing incremental predictive ability for all types of recidivism after controlling for Static-99 (Hanson et al., 2007).

\section{Protective Factors}

Despite the proliferation of empirical studies demonstrating the predictive accuracy of various risk assessment instruments, these risk tools only consider one side of the equation. Risk factors are commonly emphasised while protective factors are rarely included, potentially 
resulting in a biased, overestimation of risk (Miller, 2006; Rogers 2000; Ullrich \& Coid, 2011). Protective factors are assets and skills that an offender possesses that may improve maladaptive outcomes (Ullrich \& Coid, 2011). These strength factors may operate at various levels, including internal beliefs and attitudes, social and familial relations, and environmental and contextual factors (Haggard et al., 2001; Miller, 2006; Rogers, 2000; Ullrich \& Coid, 2011). By including protective factors within a structured risk assessment instrument, it is possible to not only estimate the probability of recidivism, but also the probability of desistence. (i.e., successful cessation of criminal behaviour). Thus, examining those offenders who were identified as high risk, but eventually desisted from crime, may provide useful information on those factors that contributed to their desistance (Haggard et al., 2001; Miller, 2006; Rogers, 2000; Ullrich \& Coid, 2011). However, much of the current research surrounding protective factors is often done with children and youth, due to the belief that adolescents are more receptive to protective influences as they are still in the process of development (Borowsky, Hoan, \& Ireland, 1997; Fitzpatrick, 1997; Resnick, 2000; Ullrich \& Coid, 2011). Hence, the research on the effects of protective factors with adult offenders remains sparse. Contributing to this lag in research is debate regarding the operational definition of protective factors. Some argue that protective factors are simply the inverse or absence of risk factors; while others argue that they are relatively distinct from risk factors, having their own direct effects on behaviour (Costa, Jessor, \& Turbin, 1999; Hawkins, Catalano, \& Miller, 1992; Ullrich \& Coid, 2011). Although the relationship between risk and protective factors is complex, examining their interplay is important in accurately predicting recidivism (Hoge, Andrews \& Leschied, 1996; Resnick, 2000; Ullrich \& Coid, 2011).

The DRAOR was originally developed to provide re-entry guidelines to assist parole and probation officers with case-management strategies (Serin et al., 2010). The DRAOR is divided 
into three main domains, which include stable risk factors, acute risk factors and protective factors. The stable and acute domains contained within the DRAOR reflect the dynamic items proposed by Hanson and Harris (2000). Some of these overlapping risk variables include victim access, hostility, substance abuse, problem solving skills, significiant social influences and emotional collapse. However, these were adjusted to relate to general and violent offenders (Yesberg, Polaschek, \& Serin, 2013).

Tamatea and Wilson (2009) examined the reliability and validity of the DRAOR with a sample of 59 offenders released into the community in New Zealand. The results of this pilot work demonstrated that the DRAOR scores changed across assessments, with recidivists having significantly lower initial and final protective scores. In addition, the pilot sample was found to have a normal distribution of scores for all three subscales and demonstrated good convergent validity with the RoC*RoI, which is an established measure of static risk related to serious reoffending (Tamatea \& Wilson, 2009). Feedback from probation officers revealed that it was a user-friendly tool that also helped to structure supervision meetings with offenders (Tamatea \& Wilson, 2009). However, a notworthy limitation to this study was the small sample size. In a more recent study, the predictive validy of the DRAOR was evaluated with a sample of high-risk offenders released into the community in New Zealand (Yesberg et al., 2013). Results demonstrated that the DRAOR stable domain $(A U C=.61)$, the acute domain $(A U C=.57)$, the protective domain $(A U C=.60)$ and the total score $(A U C=.62)$ were all able to significantly predict post-release reconvictions among offenders (Yesberg et al., 2013). Based on additional work conducted in Iowa, the protective factors contained in the DRAOR uniquely added predictive information that was able to differentiate between recidivists and non-recidivists $(A U C=.67)$. In addition, the total stable $(A U C=.60)$, the total acute $(A U C=.65)$ and the total 
DRAOR scores $(A U C=.66)$, all significantly predicted general recidivism (Serin \& Prell, 2012).

The original version of the DRAOR coincided with the research of Ullrich and Coid (2011), and many of the protective items included in the DRAOR were replicated from that study. More specifically, the study by Ullrich \& Coid (2011) examined the effects of protective factors at differing levels of risk and the stability of these protective factors over a period of three years was explored. Examining 800 male offenders released on community supervision, the study investigated protective factors hypothesized to reduce violent recidivism (Ullrich \& Coid, 2011). Based on a review of the literature and clinical expertise, Ullrich and Coid (2011), examined 15 protective factors representing support from family and peers, pro-social involvement, importance of religion, closeness to others, relationship competence, proactive behaviours/circumstantial factors. Results demonstrated that several of the hypothesized protective factors significantly reduced the likelihood of violent reoffending (Ullrich \& Coid, 2011). Regarding the effects of protective factors over time, having a place to stay upon release only had a short-term protective effect (within the first year) and did not appear to have longterm protective effects (Ullrich \& Coid, 2011). Interpersonal factors, such as social support, emotional support and spare-time with family and friends (provided they were positive social influences) demonstrated longer-lasting effects (Ullrich \& Coid, 2011). Lastly, employment, training and education demonstrated protective effects for the third year and beyond (Ullrich \& Coid, 2011). Therefore, strategies need to be developed to account for the different needs of offenders released into the community at different time intervals (Ullrich \& Coid, 2011). Regarding protective factors at differing levels of risk, the results were not significant; demonstrating that the influence of protective factors was independent of risk level (Ullrich \& Coid, 2011). That is, protective factors did not moderate the relationship between risk and 
residivism, but instead, the effects of protective factors were found whether the offender was low, moderate, or high risk for future violence. (Ullrich \& Coid, 2011).

In a qualitative study conducted by Haggard et al. (2001), high-risk offenders $(n=6)$ who had desisted from crime after a 10- year follow-up period were interviewed. The most salient factors that emerged from this qualitative study were the importance of interpersonal factors and the stability of these social support systems (Haggard, et al., 2001). Further, all of the participants indicated that desistance was a conscious, effortful process, involving major psychological, social and environmental changes (Haggard, et al., 2001). Although this qualitative approach may not offer firm conclusions regarding the significance of these factors, the results are consistent with previous quantitative reviews regarding the importance of prosocial interpersonal relationships (Ullrich \& Coid, 2011).

\section{Sex offender heterogeneity}

Sex offenders are a heterogeneous group and considering offender typologies can further enhance prediction. Sex offenders not only vary on static, criminal history profiles, such as victim characteristics and type and frequency of recidivism, but they also differ on many relevant dynamic domains such as attitudes supportive of sexual assault, deviant sexual interests, and criminal orientation (Abracen et al., 2004; Seto \& Fernandez, 2011). Therefore, differential predictors for subgroups of offenders can be expected and determining which dynamic factors are most relevant for different sex offender subtypes is a key area of research.

Although hostility and lifestyle instability are associated with sexual recidivism for both rapists and child molesters (Hanson \& Morton-Bourgon, 2005), rapists are more likely to have antisocial orientation, and higher rates and frequency of non-sexual recidivism compared to those offenders whose victims are children (Bartosh, Garby, Lewis, \& Gray, 2003; Craig \& 
Beech, 2009; Eher, Rattenberger, Schilling, \& Pfafflin, 2008; Hanson \& Bussier, 1998; Hanson et al., 2003; Harris et al., 2003; Rattenberger, Matthes, Boer, \& Eher, 2010). Regarding deviant sexual arousal, previous research has also demonstrated that child molesters have higher mean arousal scores than rapists, indicating that sexual deviancy may be more meaningful for child molesters, whereas general criminal deviance (i.e. antisocial attitudes) may be more significant for rapists (Abracen et al., 2004; Harris et al., 2003; Olver, et al., 2007; Rice \& Harris, 1997).

There is also a base rate difference for sexual recidivism among different types of sex offenders (Harris \& Hanson, 2004). For instance, rapists have a 24\% sexual recidivism rate at 15 years after release compared to a $35 \%$ sexual recidivism rate for child molesters (Harris \& Hanson, 2004). Further, sexual recidivism can be predicted in a shorter time frame for rapists, whereas sexual recidivism for child molesters is predicted with longer follow-up time periods (Bartosh et al., 2003). For instance, Craig and Beech (2009) suggest that rape is essentially "predatory antisocial behaviour" (pg. 202) and is more likely to occur within the first five years of release, whereas child molesters have an enduring propensity toward sexual deviance, which is evident over a longer period of time (Craig \& Beech, 2009).

\section{Current Study}

Despite the considerable strides achieved in the risk assessment literature, there is a paucity of research examining the relationship of dynamic and protective factors in the prediction of sexual recidivism. The DRAOR is a unique risk assessment tool as it contains both dynamic, (both stable and acute) and protective factors. The purpose of Study 1 is not simply to validate the DRAOR as a sex offender assessment tool, but also, to examine the nature of dynamic risk factors as they compare to other offender types. Study 1 will be looking at the 
utility of dynamic and protective factors in relation to sex offenders, which have been integrated into a structured risk assessment measure. Thus, this study will add to the growing body of literature relevant to the prediction of sexual recidivism, while also contributing to risk prevention and risk reduction strategies by emphasizing the importance of strength and resiliency. In Study 2, the incremental validity of the Stable-2007 and Acute-2007 will also be evaluated to determine if these measures can demonstrate an increment in predictive efficiency above that already demonstrated with static risk estimates.

\section{Hypotheses}

Hypothesis 1: It is predicted that the DRAOR will demonstrate convergent validity with the Static-99R.

Hypothesis 2: It is predicted that both the Acute-2007 and Stable-2007 will demonstrate convergent validity with the Static-99R.

Hypothesis 3: It is predicted that the DRAOR will significantly predict any sexual recidivism, any violent recidivism and technical violations.

Hypothesis 4: It is predicted that the Stable-2007 and Acute-2007 will significantly predict any sexual recidivism, any violent recidivism and technical violations.

Hypothesis 5: It is predicted that the DRAOR will predict any sexual recidivism, any violent recidivism and technical violations above and beyond the Static-99R.

Hypothesis 6: It is predicted that both the Acute-2007 and Stable-2007 will predict any sexual recidivism, any violent recidivism and technical violations above and beyond the Static-99R. Hypothesis 7: It is predicted that the DRAOR Protective domain will moderate the relationship between static risk scores and recidivism. 


\section{Methodology}

\section{Sample}

Using archival data provided from the Iowa Department of Corrections database, two separate offender samples were included. The first sample included 212 male adult sex offenders; 210 of these offenders had Static-99R scores, with 193 of these offenders having at least one DRAOR assessment. The second sample included 227 male adult sex offenders; 210 of these offenders had Static-99R assessment. 206 of these offenders had at least one Stable-2007 assessment, and 225 had at least one Acute-2007 assessment. ${ }^{12}$

Study 1 Demographics. Descriptive statistics for this sample are displayed in Table 1. The mean age of the entire sample at the time of release was 36.18 years $(S D=14.55)$. The ethnic composition was primarily Caucasian (88.2\%), with a smaller minority being AfricanAmerican (11.3\%). Further, $45 \%$ of the sample was classified as rapists, with $38 \%$ classified as child molesters.

Based on Static-99R risk score prior to release, slightly less than half of the sample was rated as low-moderate risk (45.3\%) with only a small amount of offenders rated as high risk (9\%). Table 2 displays the Static-99R risk groups.

\footnotetext{
${ }^{1}$ Because this is archival data, it was not possible to include a priori hypotheses regarding differences in predictive accuracy and survival time among the different subgroups of sex offenders (i.e. rapists vs. child molesters).

${ }^{2}$ Although the ideal approach would be to examine the DRAOR, Stable-2007, Acute-2007, and Static-99R within the same sample, this was not possible as the two samples included different sex offenders.
} 
Table 1

Sample Demographics-Study 1

\begin{tabular}{lcc}
\hline Variable & $\mathrm{n}$ & $\%$ \\
\hline Age at Release $M(S D)$ & $36.18(14.55)$ & 22.2 \\
Any Prior Sex Offences & 46 & \\
Offender Type & & 45.8 \\
Rapist & 93 & 42.4 \\
Child Molester & 86 & 5.4 \\
Unknown & 11 & \\
Ethnicity & & 88.2 \\
Caucasian & 179 & 11.3 \\
African-American & 23 & .5 \\
Aboriginal & 1 & \\
Marital Status & & 1.0 \\
Common-Law & 2 & 15.3 \\
Divorced & 31 & 24.1 \\
Married & 49 & 46.8 \\
Single & 95 & .5 \\
Widowed & 1 & \\
Separated & 3 & \\
\hline
\end{tabular}

Table 2

Static-99R Risk Groups-Study 1

\begin{tabular}{lcc}
\hline Variable & $\%$ & $\mathrm{n}$ \\
\hline Low & 28.6 & 59 \\
Low-Moderate & 45.3 & 92 \\
Moderate-High & 20.7 & 42 \\
High & 9 & 9 \\
\hline
\end{tabular}

Study 2 Demographics. Descriptive statistics for this sample are displayed in Table 3.

The mean age of the entire sample at the time of release was 33.51 years $(\mathrm{SD}=12.24)$. The 
ethnic composition was primarily Caucasian (87.2\%), with a smaller minority being AfricanAmerican (11.1\%). Further, $45.4 \%$ of the sample was classified as rapists, with $38.2 \%$ classified as child molesters. Based on their Static-99R risk score prior to release, slightly less than half of the sample was rated as low-moderate risk (39.1\%) with only a small amount of offenders rated as high risk (10.1\%). Table 4 displays the Static-99R risk groups.

Table 3

Sample Demographics- Study 2

\begin{tabular}{lcc}
\hline Variable & $\mathrm{n}$ & $\%$ \\
\hline Age at Release $M(S D)$ & $33.51(12.24)$ & 22.2 \\
Any Prior Sex Offences & 46 & \\
Offender Type & 79 & 45.4 \\
Rapist & 94 & 38.2 \\
Child Molester & 12 & 5.8 \\
Unknown & & \\
Ethnicity & 182 & 87.9 \\
Caucasian & 23 & 11.1 \\
African-American & 2 & 1.0 \\
Aboriginal & & \\
Marital Status & 3 & 1.4 \\
Common-Law & 35 & 16.9 \\
Divorced & 37 & 17.9 \\
Married & 93 & 44.9 \\
Single & 2 & 1.0 \\
Widowed & & \\
\hline
\end{tabular}


Table 4.

Static-99R Risk Groups-Study 2

\begin{tabular}{lcc}
\hline Variable & $\%$ & $\mathrm{n}$ \\
\hline Low & 22.2 & 46 \\
Low-Moderate & 39.1 & 81 \\
Moderate-High & 20.8 & 43 \\
High & 10.1 & 21 \\
\hline
\end{tabular}

\section{Measures}

Static-99R (Hanson \& Thornton, 2000; Helmus, Thornton, Hanson \& Babchishin,

2012). The Static-99R is an actuarial risk assessment instrument used to estimate risk of sexual recidivism among adult sex offenders. The Static-99R is identical to the Static-99, but with revised age weights. Since criminal behaviour typically declines with age, the Static-99 did not account for age at release, resulting in an over-estimation of risk for older offenders (Helmus, et al., 2012). Specifically, the Static-99 was developed after combining the items from the Rapid Assessment for Sex Offense Recidivism (RRASOR), and the Structured Anchored Clinical Judgement (SACJ; Hanson \& Thornton, 2000) The Static-99R includes 10 static items: young age at time of assessment, any live-in intimate relationship for 2 or more years, any prior or index offence of non-sexual violence, prior charges or convictions for sexual offences, prior sentencing dates (excluding index), any convictions for non-contact sex offences, any unrelated victims, any stranger victims and any male victims. The total score ranges from -3 to 12 , with total scores arranged in one of four risk categories: low (- 3 to 1), moderate-low (2 to 3 ), moderate-high (4 to 5), and high (6+). The Static-99R is a moderate predictor of sexual recidivism $(A U C=.68 ; 95 \% \mathrm{CI}=[.67, .70]$; Babchishin, Hanson, \& Helmus, 2011) 
Stable-2007 (Hanson et al., 2007). The Stable-2007 is an empirical instrument used to assess dynamic predictors of sexual recidivism among adult sex offenders. The Stable-2007 includes 13 stable items: significant social influences, capacity for relationship stability, emotional identification with children, hostility toward women, general social rejection, lack of concern for others, impulsivity, poor problem solving skills, negative emotionality, sex drive and sex preoccupation, use of sex as coping, deviant sexual interests and co-operation with supervision. Scores on the Stable-2007 range from 0-26 (out of 24 for those without a child victim), with total scores arranged in one of three risk categories: low (0-3), moderate (4-11), and high (12+). The Stable-2007 has shown good internal consistency $(\alpha=.80)$ and is a moderate predictor of sexual recidivism $(A U C=.67 ; 95 \% \mathrm{CI}=[.59, .74]$; Hanson et al., 2007). Further, the Stable-2007 scores were highly consistent between the first and second assessment $($ ICC $=.79$; Hanson et al., 2007).

Acute-2007 (Hanson et al., 2007). The Acute- 2007 is an empirical actuarial instrument used to assess dynamic predictors of sexual recidivism among adult sex offenders. It includes seven acute dynamic items: victim access, hostility, sexual preoccupation, rejection of supervision, emotional collapse, collapse of social supports and substance abuse. The first four items (victim access, hostility, sexual preoccupation, and rejection of supervision) are summed to estimate sexual and non-sexual recidivism (called the sex/violence subscale), whereas all seven items are summed to estimate general recidivism. Scores on the sexual and violence risk factor range from 0-4, with total scores arranged in one of three categories: low priority $(0)$, moderate priority (1), and high priority (2+). Scores on the general criminality factor range from $0-7$, with total scores arranged in one of three categories: low priority (0), moderate priority (1-2), and high priority (3+). Acute-2007 assessments are typically conducted at each supervision meeting. 
The Acute-2007 has shown good internal consistency $(\alpha=.72)$ and is a good predictor of sexual recidivism $(\mathrm{AUC}=.72 ; 95 \% \mathrm{CI}=[.60, .84]$; Hanson et al., 2007).

\section{Dynamic Risk Assessment for Offender Re-Entry (DRAOR; Serin, 2007; Serin et}

al., 2010). The DRAOR is an 19-item risk assessment instrument organized into 3 domains: stable risk indicators (peer associations, attitudes towards authority, self-regulation, problemsolving, sense of entitlement, and attachment with others), acute risk indicators (substance abuse, anger/hostility, opportunity/access to victims, negative mood, employment, interpersonal relationships, living situation) and protective factors (responsive to advice, prosocial identity, high expectations, costs/benefits, social support, and social control). The stable, acute and protective domains are scored on a 3-point scale. For the stable and acute factors, a score of 0 represents no problem, 1 represents a slight or possible problem, and a score of 2 represents a definite problem. Regarding protective factors, 0 indicates the item is not a protective factor, a score of 1 indicates it is a slight or possible asset, and a score of 2 indicates the item is a definite asset. The DRAOR also includes risk scenarios that provide probation officers with information about the most likely reoffending scenario (i.e. 'what may go wrong'). This section provides the probation officers an opportunity to rate how concerned they are that the offender will reoffend, ranging from 1 (Not concerned) to 6 (Very concerned). Based on this rating, the probation officer can increase, decrease or maintain the frequency of supervision contacts. Lastly, the DRAOR provides a section where the evaluators can identify any additional factors that may be relevant for increasing or decreasing risk. Probation and parole officers at each supervision meeting conduct the DRAOR assessments, typically monthly. Based on pilot work conducted in New Zealand and Iowa, the DRAOR is a moderate predictor of general recidivism $(A U C=.66$; $95 \% \mathrm{CI}=[.62, .69])$. In addition, the total stable scores $(A U C=.60 ; 95 \% \mathrm{CI}=[.56, .64])$, the total 
acute scores $(A U C=.65 ; 95 \% \mathrm{CI}=[.61, .69])$ and the total protective scores $(A U C=.67 ; 95 \% \mathrm{CI}$ $=[.63, .70])$, have all demonstrated moderate predictive accuracy for technical violations and general recidivism (Serin \& Prell, 2012).

\section{Outcome Data: Study 1 and 2}

All data collection and coding were completed by staff from the Iowa Department of Corrections. Prior to receiving the data, the data was stripped of identifiers and assigned a unique identification number. Outcome criteria included any sexual reoffending, any violent reoffending (excluding sexual) as well as technical violations (e.g. substance abuse violations, curfew violations). ${ }^{34}$ Sexual recidivism was defined as a new offense that was sexual in nature and involved physical contact with the victim. Recidivism was coded based upon conviction information contained in the Iowa ICON system. Time at risk was calculated for each of the outcome variables based on the time between release from custody and the first recidivism incident. For those offenders with no recidivism data, time at risk was calculated until the end of the follow-up period (June 16, 2013).

\section{Analytic Strategy}

Correlational Analyses. Correlational analyses were conducted in order to investigate the convergent validity of the DRAOR in relation to the Static-99R. In addition, convergent validity was examined among the Stable-2007, Acute-2007 and Static-99R.

Receiver Operating Characteristics (ROC). This analysis was used to examine the predictive accuracy of the Static-99R, DRAOR, Stable-2007 and Acute-2007. ROC analyses are one of the most commonly employed statistical techniques to assess how accurate risk

\footnotetext{
${ }^{3}$ The outcome criterion for both studies was defined consistent with similar research (Hanson \& Morton-Bourgon, 2009; Hanson et al., 2007). However, this does not imply that sexual violence is less serious.

${ }^{4}$ The reason for probation and parole violations resulting in reconviction was not examined due to insufficient information.
} 
assessment instruments are at predicting recidivism. The ROC analyses generate the Area Under the (ROC) Curve (AUC). ROC analyses assess both sensitivity and specificity of a measure (Rice \& Harris, 2005). Sensitivity of a measure refers to the ability to correctly predict recidivism (hit rate), whereas specificity refers to a measures ability to correctly identify a nonrecidivist (Harris \& Rice, 2003). Thus, ROC curves plot the sensitivity (hit rate) against false alarms (1-specificity; Craig \& Beech, 2009; Harris \& Rice, 2003). The AUC statistic is interpreted as the probability that a randomly selected recidivist would have a higher risk score than a randomly selected non-recidivist (Rice \& Harris, 2005). AUC values range from .50 to 1.0, with an $A U C$ value of .50 indicating predictive accuracy no better than chance level and an AUC value of 1.0 indicates perfect prediction (Rice \& Harris, 2005). Further, AUCs are analogous to common language effect sizes, resulting in easy interpretation (Rice \& Harris, 2005). Typically, $A U C s$ of .55 to .63 are considered a small effect; $A U C s$ of .64 to .70 values are considered a medium effect; and $A U C$ values of .71 and higher are indicative of a large effect (Rice \& Harris, 2005). ROC analyses have the advantage of typically being unaffected by low base rates, and selection ratios (i.e. the proportion of offenders predicted to recidivate; Rice \& Harris, 2005). This is particularly pertinent with sex offenders as this group of offenders frequently has low base rates.

Cox Regression Survival Analysis. In order to examine the incremental validity of the dynamic measures over and above static risk, a series of cox regression survival analyses were performed. Survival analyses are statistical procedures used for measuring the length of time until an event occurs (Tabachnick \& Fidell, 2007). Specifically, it measures the time between release and recidivism or the end of the follow-up period (Tabachnick \& Fidell, 2007). Cox regression is a function of survival analyses, which applies regression methodology to survival 
data (Tabachnick \& Fidell, 2007). Thus, this approach allows multiple predictors to be measured simultaneously in order to determine their independent and unique contributions to the outcome variable (Tabachnick \& Fidell, 2007). This analytic strategy was chosen over logistic regression, as cox regression survival analysis is able to incorporate variable follow-up times and sample censoring (Brown et al., 2009; Harris et al., 2002; Knight \& Thornton, 2007).

Moderated Cox Regression Survival Analysis. Cox regression survival analysis was used to examine if the DRAOR protective domain will moderate the relationship between risk and recidivism. The focal IV was identified as the total risk score on the Static-99R, whereas the DRAOR protective domain was identified as the moderator. First, the independent effects of risk and protective factors (i.e. main effects) were entered simultaneously in the first block, while the interaction term of Total Risk x Total Protective score was entered in the second block. This analysis was undertaken to determine if higher scores on the protective domain would mitigate the risk for future recidivism. The two predictors are said to interact (i.e. have a joint effect) in their accounting for variance in the outcome when it is significant over and above any additive combination of their separate effects (i.e. main effects; Cohen et al., 2003). 


\section{Results: Study 1}

\section{Data Screening}

Missing Values. Prior to analysis, all variables were examined for accuracy of data entry and the presence of missing values. Some of the earlier DRAOR case plans do not have individual item scores but only total domain scores. However, recording individual item scores became standard practice after August 2011. Consequently, all assumptions and subsequent analyses were tested at the DRAOR subscale level, as there were too many missing item scores. Offenders were excluded if they were less than 18 years old at the time of release or less than 16 years old when they committed the index offence $(n=2)$. Further, since the mean length of time between release and the first DRAOR assessment was 7.68 months $(S D=10.70)$, cases were excluded if they recidivated before their first DRAOR assessment $(n=7)$. The exclusion of these cases reduced the sample from 212 to 203 sex offenders. All subsequent analyses were conducted with this reduced sample. With the exception of these excluded cases, there was no other missing data in the variables of interest.

Distribution. All variables were examined for outliers, normality, linearity and homoscedasticity. An examination of box plots and standardized z-scores revealed that there were no univariate outliers. Normality was screened through an examination of probability plots and histograms, which revealed no visible departure fom normality. In adition, the standardized values of both skewness and kurtosis did not exceed 3.29 (two-tailed) using an alpha level of .001 . Homoscedasticity and linearity were examined among the variables through visual examination of bivariate scatterplots and residual plots (plots standardized predicted values against standardized residuals). Results demonstrated that all variable pairs tested in regression were linearily related. Further, no variables visibly showed clear departures from 
homoscedasticity, as the variance of one variable was the same at all values of the other variables.

Multivariate outliers were analyzed through Mahalanobis' distance, and influence values. Results from Mahalanobis' distance, which measures the distance of cases from the means of the predictor variables, revealed that there was only one case that exceeded the critical value of $20.51(d f=5, \alpha=.001 ;$ Tabachnick \& Fidell, 2007). The case was retained, as its removal did not alter the overall statistical significance of the results. In survival analysis, the DFBeta statistic can also be examined to determine if any cases had an influence on the parameters of the regression model. That is, this diagnostic statistic is calculated for every case, which indicates how much individual regression coefficients would change if the case were not included in the sample. Values larger than 1 indicate that a case may have a large influence on the parameters of the regression model; however, all of the DFBeta values were below 1, indicating no multivariate outliers.

Proportional Hazards Assumption. The proportionality of hazards is specific to Cox regression. It assumes that the shape of the survival function over time is the same for all cases (Tabachnick \& Fidell, 2007). If this assumption is violated, it implies there is an interaction between covariates and time (Tabachnick \& Fidell, 2007). This assumption was tested using the $\log$ minus $\log$ plots of the hazard function. This assumption was not violated as the lines were parallel and did not cross each other.

Recidivism Rates. Table 5 displays the recidivism rates for the whole sample and sex offender subgroups. The maximum follow-up period was 105 months $(M=21.61, S D=13.80)$. Only $4.4 \%$ of the sample recidivated with a new sexual crime, whereas $36.9 \%$ recidivated with a technical violation. Due to the low prevalence rates for sexual recidivism, the results for this 
outcome need to be considered cautiously. Relatedly, only one offender recidivated with a violent offence. Reoffending categories with only one or two recidivists would preclude any meaningful conclusions. Therefore, subsequent analysis only examined parole violations and any sexual reoffending. The mean time to first rule violation was 17 months $(S D=14.23)$, whereas the mean time to first sexual recidivism was 21 months $(S D=13.73)$.

Table 5

Recidivism Rates

\begin{tabular}{lccc}
\hline Recidivism Type & $\begin{array}{c}\text { Whole Sample } \\
(\mathrm{n}=203)\end{array}$ & Rapists $(\mathrm{n}=93)$ & Child Molesters $(\mathrm{n}=86)$ \\
& $\%(\mathrm{n})$ & $\%(\mathrm{n})$ & $\%(\mathrm{n})$ \\
\hline Parole Violations & $36.9(75)$ & $14.3(29)$ & $16.7(34)$ \\
Any Sexual & $4.4(9)$ & $2.5(5)$ & $1.0(2)$ \\
\hline
\end{tabular}

\section{Measures: Descriptives}

Table 6 displays the descriptive statistics for each measure. In addition, independent samples $t$-tests were conducted to assess mean differences between rapists and child molesters on static risk and each DRAOR domain. Table 7 indicates that rapists had higher mean scores on the Static-99R compared to child molesters. However, there was no significant difference on the DRAOR total and subscale sores between the two groups. 
Table 6

Descriptive statistics for Static-99R and DRAOR

\begin{tabular}{cccc}
\hline Measure & Mean & SD & Range \\
\hline Static-99R & 2.36 & 2.14 & $-3-9$ \\
DRAOR & & & \\
Stable Total & 5.49 & 2.79 & $0-12$ \\
Acute Total & 5.97 & 2.62 & $0-13$ \\
Protective Total & 6.10 & 3.19 & $0-12$ \\
Total & 5.36 & 7.30 & $-12-24$ \\
\hline
\end{tabular}

Table 7

Comparisons between Rapists and Child Molesters

\begin{tabular}{lcccc}
\hline Variable & $\begin{array}{c}\text { Rapists } \\
M(S D)\end{array}$ & $\begin{array}{c}\text { Child Molesters } \\
M(S D)\end{array}$ & $t$ & $p$ \\
\hline \multicolumn{1}{c}{ Static-99R } & $\mathbf{2 . 9 0 ( \mathbf { 1 . 5 7 } )}$ & $\mathbf{1 . 5 5 ( 2 . 2 8 )}$ & $\mathbf{- 4 . 3 9}$ & $\mathbf{. 0 0 0}$ \\
DRAOR & & & & \\
$\quad$ Stable Total & $5.09(2.72)$ & $5.83(2.78)$ & 1.69 & .092 \\
Acute Total & $5.70(2.63)$ & $6.09(2.56)$ & .948 & .345 \\
Protective Total & $6.36(2.97)$ & $6.19(3.30)$ & -.353 & .725 \\
Total & $4.43(6.94)$ & $5.72(7.50)$ & 1.14 & .256
\end{tabular}

Note. Bonferroni correction of $p<05 / 5=.01$. Bold denotes significance after Bonferroni Correction.

Comparisons between recidivists and non-recidivists. Comparisons were made between those who recidivated and those who did not recidivate for both parole violations and sexual recidivism. A series of independent sample $t$-tests were used to compare scores on the DRAOR domains and Static-99R between the two groups. A Bonferroni correction was made for each $t$-test in order to maintain the family-wise error rate at $\alpha=.05$. 
As can be seen in Table 8, those that reoffended with a parole failure had significantly higher mean scores on each of the DRAOR domains (including the overall score) than those who desisted. Further, the recidivist group had higher static scores than the non-recidivist group. However, with regard to sexual recidivism, a different pattern emerged. No differences were found on any of the DRAOR domains or Static-99R scores between recidivists and nonrecidivists. Those that recidivated during the follow-up period had similar mean scores on all the measures. Results are displayed in Table 9.

Table 8.

Parole Violations: Comparisons between Recidivists and Non-recidivists

\begin{tabular}{|c|c|c|c|c|}
\hline Variable & $\begin{array}{c}\text { Recidivists } \\
M(S D)\end{array}$ & $\begin{array}{c}\text { Non-recidivists } \\
M(S D)\end{array}$ & $t$ & $p$ \\
\hline Static-99R & $2.97(1.89)$ & $1.99(2.16)$ & -3.05 & .003 \\
\hline \multicolumn{5}{|l|}{ DRAOR } \\
\hline Stable Total & $6.75(2.59)$ & $4.81(2.66)$ & -4.79 & .000 \\
\hline Acute Total & $6.92(2.70)$ & $5.45(2.44)$ & -3.78 & .000 \\
\hline Protective Total & $5.29(3.15)$ & $6.55(3.14)$ & 2.58 & .01 \\
\hline Total & $8.38(7.05)$ & $3.71(6.92)$ & -4.35 & .000 \\
\hline
\end{tabular}

Note. Bonferroni correction of $p<05 / 5=.01$. Bold denotes significance after Bonferroni Correction. 
Table 9.

Sexual Recidivism: Comparisons between Recidivists and Non-recidivists

\begin{tabular}{lcccc}
\hline Variable & $\begin{array}{c}\text { Recidivists } \\
M(S D)\end{array}$ & $\begin{array}{c}\text { Non-recidivists } \\
M(S D)\end{array}$ & $t$ & \\
\hline \multicolumn{1}{c}{ Static-99R } & $3.33(1.63)$ & $2.31(2.13)$ & -1.17 & .244 \\
DRAOR & & & \\
Stable Total & $5.67(3.32)$ & $5.48(2.78)$ & -.15 & .878 \\
Acute Total & $6.67(3.44)$ & $5.94(2.60)$ & -.663 & .508 \\
Protective Total & $6.33(3.72)$ & $6.09(3.18)$ & -.179 & .858 \\
Total & $6.00(9.85)$ & $5.33(7.23)$ & -.218 & .828 \\
\end{tabular}

Note. Bonferroni correction of $p<05 / 5=.01$. Bold denotes significance after Bonferroni correction.

Convergent Validity. To examine convergent validity, correlational analyses were conducted between the DRAOR subscales and total score and the Static-99R to determine if the DRAOR is assessing similar items contained in the Static-99R. As can be seen in Table 10, all correlations among measures were significant at the $p<.05$ level. The largest correlation observed was between the Static-99R and the DRAOR total domain $(r=.26)$.

Table 10.

Correlation Matrix

\begin{tabular}{lcclc}
\hline Measures & Stable & Acute & Protective & Total \\
\hline Static-99R & $.23 * *$ & $.17^{*}$ & $-.24 * *$ & $.26^{* *}$ \\
DROAR Stable & & $.72^{* *}$ & $-.57^{* *}$ & $.89^{* *}$ \\
DRAOR Acute & & & $-.47^{* *}$ & $.84^{* *}$ \\
DRAOR Protective & & & $-.82^{* *}$ \\
\hline$* p<.05 . * * p<.01$. & & &
\end{tabular}


Predictive Validity. Table 11 displays bivariate correlations (Pearson's $r$ ), Cohen's $d$, and $A U C$ values for each DRAOR domain (including the total score) and total Static-99R scores for both recidivism outcomes. It is important to note that although Pearson's $r$ values are a common measure of association between a predictor and an outcome, point-biserial correlation assumes a base rate of $50 \%$ in the outcome (Rice \& Harris, 2005). However, the base rate of both sexual recidivism and rule violations was well below 50\%. Therefore, $A U C$ analyses were also conducted to examine the predictive accuracy of these measures in predicating sexual recidivism and rule violations. The results show that the Static-99R and all of the DRAOR domains (including the overall score) were predictive of rule violations, with $A U C s$ ranging from .61 to .69. Although there appear to be differences in $A U C$ values for predicting technical violations, there was a clear overlap in confidence intervals between the variables, indicating that none of the variables was significantly better at prediction than the others. Table 11 also illustrates that only the Static-99R was predictive of sexual recidivism $(A U C=.69)$, whereas none of the DRAOR domains were significantly related to this outcome, with $A U C s$ ranging from .46 to .53. 
Table 11

Predictive Accuracy (ROC)

\begin{tabular}{|c|c|c|c|c|c|c|}
\hline \multirow[b]{2}{*}{ Variable } & \multirow[b]{2}{*}{$r$} & \multirow[b]{2}{*}{$d$} & \multirow[b]{2}{*}{ AUC } & \multirow[b]{2}{*}{$S E$} & \multicolumn{2}{|c|}{ Asymptotic $95 \%$ CI } \\
\hline & & & & & Lower & Upper \\
\hline & & \multicolumn{5}{|c|}{ Parole Violations } \\
\hline Static-99R & $.24 * *$ & .51 & $.64 * * *$ & .04 & .56 & .72 \\
\hline \multicolumn{7}{|l|}{ DRAOR } \\
\hline Stable Total & $.33 * *$ & .70 & $.69 * * *$ & .04 & .62 & .78 \\
\hline Acute Total & $.27 * *$ & .54 & $.65 * * *$ & .04 & .57 & .74 \\
\hline Protective Total & $-.18^{*}$ & .40 & $.61 * * *$ & .04 & .52 & .69 \\
\hline \multirow[t]{2}{*}{ Total } & $.31 * *$ & .66 & $.68 * * *$ & .04 & .60 & .76 \\
\hline & & \multicolumn{5}{|c|}{ Sexual Recidivism } \\
\hline Static-99R & $.16^{*}$ & .70 & $.69 * *$ & .08 & .53 & .85 \\
\hline \multicolumn{7}{|l|}{ DRAOR } \\
\hline Stable Total & .01 & .04 & .51 & .12 & .26 & .75 \\
\hline Acute Total & .05 & .11 & .53 & .12 & .30 & .75 \\
\hline Protective Total & .01 & -.14 & .46 & .13 & .21 & .71 \\
\hline Total & .02 & -.14 & .46 & .12 & .22 & .70 \\
\hline
\end{tabular}

Note. $\mathrm{AUC}=$ area under the curve; $\mathrm{SE}=$ standard error; $\mathrm{CI}=$ confidence interval.

$* p<.05 . * * p<.01 .{ }^{* * *} p<.001$.

Cox Regression Survival Analysis. A series of cox regression analyses were conducted at both the univariate and multivariate level to examine the association between static and dynamic variables and recidivism while accounting for the time until the event. More specifically, analyses were conducted at the univariate level to determine which variables were related to survival time. Those variables that were individually related to survival time were entered into a series of hiearchal cox regression survival analyses to examine the incremental 
validy of the dynamic variables over and above static risk. When examining predictive validity in applied risk assessment, demonstrating incremental validity is important as this form of validity is concerned with determining whether a measure can add to the prediction of an outcome over and above what can be predicted by other sources (Babchishin, Hanson, \& Helmus, 2011).

When looking at the results, examining the regression coefficients will provide an indication of length of survival time. Predictors with positive coefficients (B) indicate that recidivism occurred more quickly after release; with negative coefficients indicating that recidivism occurred later after release (Tabachnick \& Fidell, 2007). In addition, cox regression estimates relative risk ratios (hazard rate; $\operatorname{Exp}[\mathrm{B}]$ ), which provide an indication of the likelihood of an event (Tabachnick \& Fidell, 2007). For instance, an Exp[B] of 1.60 would mean that a one unit increase in the total score would yield a $60 \%$ increase in the likelihood of recidivism. Lastly, the log likelihood statistic represents the degree to which the estimated survival model fits the observed data, with smaller log likelihood estimates indicating a better fit (Tabachnick \& Fidell, 2007).

Univariate Results. A series of cox regression survival analyses was conducted the univariate level to determine if the dynamic domains and Static-99R scores were significantly related to survivial time for each reoffence outcome. Specifically, five cox regression survival analyses were individually conducted with the Static-99R total score and each of the DRAOR domains to identify which variables were independently related to survival time for sexual recidivism and parole failures. Results varied depending on the recidivism criteria. As seen in Table 12, only the Static-99R $(-2 \log$ likelihood $=78.30), \chi^{2}(1)=4.88, p=.002$, significantly predicted time until sexual recidivism, indicating that having a higher score on this measure was 
related to a decrease in survival time, with every unit increase in the total score yielding a $40 \%$ increase in risk of sexual reoffending.

In contrast, the DRAOR stable domain $(-2 \log$ likelihood $=580.79), \chi^{2}(1)=30.93, p=$ $.000)$, acute domain $(-2 \log$ likelihood $=589.24), \chi^{2}(1)=22.486, p=.000$, protective domain $(-2$ $\log$ likelihood $=600.25), \chi^{2}(1)=11.47, p=.001$, the DRAOR total score $(-2$ log likelihood $=$ 584.482), $\chi^{2}(1)=27.24, p=.000$, and the Static-99R $(-2 \log$ likelihood $=703.27), \chi^{2}(1)=10.51$, $p=.001$, all significantly predicted time to parole violations. Results are displayed in Table 13 . Given that the regression coefficients for Static-99R scores and DRAOR risk domains were positive, those individuals with higher scores failed at a faster rate than those with lower scores. With a negative coefficient, higher scores on the DROAR protective domain were related to an increase in survival time. Further, the likelihood of reoffending was decreased by approximately $12 \%$ with every one-point increase in protective scores.

Table 12

Cox Regression Survival Analysis Predicting Sexual Recidivism: Univariate Analysis

\begin{tabular}{lcccccccc}
\hline & & & & & & & \multicolumn{3}{c}{$95 \%$ CI for $\operatorname{Exp}(B)$} \\
\cline { 3 - 8 } Variable & $B$ & $S E$ & Wald & $d f$ & $p$ & $\operatorname{Exp}(B)$ & $\begin{array}{c}\text { Lower } \\
\text { Bound }\end{array}$ & Uound \\
\hline Static-99R & .34 & .15 & 5.21 & 1 & .02 & 1.41 & 1.05 & 1.89 \\
DRAOR & & & & & & & & \\
$\quad$ Stable Total & .15 & .16 & .84 & 1 & .36 & 1.19 & .84 & 1.59 \\
Acute Total & .27 & .18 & 2.39 & 1 & .12 & 1.31 & .93 & 1.86 \\
Protective Total & -.05 & .12 & .20 & 1 & .65 & .95 & .75 & 1.19 \\
$\quad$ Total & .06 & .06 & 1.16 & 1 & .28 & 1.06 & .95 & 1.19 \\
\hline
\end{tabular}


Table 13

Cox Regression Survival Analysis Predicting Parole Violations: Univariate Analysis

\begin{tabular}{lcccccccc}
\hline & & & & & & & \multicolumn{3}{c}{$95 \%$ CI for $\operatorname{Exp}(B)$} \\
\cline { 3 - 8 } Variable & $B$ & $S E$ & Wald & $d f$ & $p$ & $\operatorname{Exp}(B)$ & $\begin{array}{c}\text { Lower } \\
\text { Bound }\end{array}$ & $\begin{array}{c}\text { Upper } \\
\text { Bound }\end{array}$ \\
\hline Static-99R & .18 & .06 & 10.16 & 1 & .001 & 1.19 & 1.07 & 1.34 \\
DRAOR & & & & & & & & \\
Stable Total & .25 & .05 & 30.22 & 1 & .000 & 1.29 & 1.18 & 1.41 \\
Acute Total & .24 & .05 & 22.24 & 1 & .000 & 1.27 & 1.15 & 1.39 \\
Protective Total & -.13 & .04 & 11.23 & 1 & .001 & .88 & .81 & .95 \\
Total & .09 & .17 & 27.32 & 1 & .000 & 1.09 & 1.06 & 1.13 \\
\hline
\end{tabular}

Multivariate Results. All static and dynamic variables that were found to be individually related to survival time were retained for subsequent analyses. Since only the Static-99R significantly predicted time until sexual recidivism, only parole violations as the outcome variable were examined. To examine the incremental validity of the dynamic variables over and above static risk, five hierarchal cox regression analyses were computed. In each of the models, the Static-99R was entered first in the first block, with each dynamic variable entered in the second block to determine if the dynamic predictors contributed unique variance in the outcome while controlling for static risk. In a final model, the Static-99R was entered in the first block, with each of the DRAOR domains entered together in the second block. Results are displayed in Table 14.

For the first comparison, when the Static-99R total score was entered in the first block, the overall model was significant $(-2 \log$ likelihood $\left.=601.624), \chi^{2}(1)=8.505, p=.004\right)$. Adding the DRAOR stable domain after accounting for static risk significantly improved the predictive 
accuracy of the model, while also accounting for unique variance in the outcome $(-2 \log$ likelihood $=575.241), \chi^{2}$ change $(1)=26.383, p=.000$. However, Table 14 reveals that only the DRAOR stable domain emerged as a significant predictor in the second block, with the Static99R total score losing significance in predicting the outcome. In the next model, Static-99R scores were again entered in the first step $(-2 \log$ likelihood $=601.624) \chi^{2}(1)=8.505, p=.004$, and scores on the DRAOR acute domain entered in the second block ( -2 log likelihood $=$ $582.691), \chi^{2}$ change $(1)=18.933, p=.000$. This also significantly improved the prediction of recidivism, with the acute domain accounting for unique variance in the outcome. Therefore, the DRAOR acute domain significantly predicted survival time after adjusting for static risk, however, static risk does not predict survival time after adjusting for the dynamic. In Model 3, Static-99R scores were entered in the first step $(-2 \log$ likelihood $=601.624), \chi^{2}(1)=8.505 p=$ .004. Adding the DRAOR protective domain after accounting for static risk significantly improved the predictive accuracy of the model $(-2 \log$ likelihood $=592.444), \chi^{2}$ change $(1)$ $=9.180, p=.002$. In contrast with the previous models, both Static-99R scores and protective scores emerged as significant predictors, with each adding incrementally to one another. In Model 4, Static-99R scores were again entered in the first step $(-2 \log$ likelihood $=601.624), \chi^{2}$ $(1)=8.505 p=.004$, with DRAOR total scores entered in the second block $(-2$ log likelihood $=$ 578.364), $\chi^{2}$ change $(1)=23.260, p=.000$; significantly improving the prediction of parole violations. In addition, only the DRAOR total score emerged as a significant predictor. Therefore, results indicate that all of the DRAOR domains incrementally enhanced the predictive validity of each of the models beyond that achieved for static risk.

For the final model, Static-99R scores were again entered in the first step (-2 log likelihood $=601.62), \chi^{2}(1)=8.505 p=.004$, with all of the DRAOR subscales entered together 
in the second block $(-2 \log$ likelihood $=574.285), \chi^{2}$ change $(3)=27.339, p=.000$. Although the results show that as a set, the covariates significantly predicted survival time, the DROAR stable domain was the only variable that emerged as a significant predictor, whereas the rest of the covariates failed to reach statistical significance. 
Table 14

Cox Regression Survival Analysis Predicting Parole Violations: Multivariate Analysis

\begin{tabular}{|c|c|c|c|c|c|c|c|c|}
\hline \multirow[b]{2}{*}{ Variable } & \multirow[b]{2}{*}{$B$} & \multirow[b]{2}{*}{$S E$} & \multirow[b]{2}{*}{ Wald } & \multirow[b]{2}{*}{$d f$} & \multirow[b]{2}{*}{$p$} & \multirow[b]{2}{*}{$\operatorname{Exp}(B)$} & \multicolumn{2}{|c|}{$95 \%$ CI for $\operatorname{Exp}(B)$} \\
\hline & & & & & & & $\begin{array}{l}\text { Lower } \\
\text { Bound }\end{array}$ & $\begin{array}{l}\text { Upper } \\
\text { Bound }\end{array}$ \\
\hline \multicolumn{9}{|l|}{ Block 1} \\
\hline Static-99R & .17 & .06 & 8.22 & 1 & .004 & 1.19 & 1.06 & 1.34 \\
\hline \multicolumn{9}{|l|}{ Block 2} \\
\hline Static-99R & .09 & .06 & 2.09 & 1 & .15 & 1.09 & .97 & 1.23 \\
\hline DRAOR Stable & .24 & .05 & 25.79 & 1 & .000 & 1.27 & 1.16 & 1.40 \\
\hline \multicolumn{9}{|l|}{ Block 1} \\
\hline Static-99R & .17 & .06 & 8.22 & 1 & .004 & 1.19 & 1.06 & 1.34 \\
\hline \multicolumn{9}{|l|}{ Block 2} \\
\hline Static-99R & .12 & .07 & 3.54 & 1 & .06 & 1.13 & .99 & 1.29 \\
\hline DRAOR Acute & .21 & .05 & 18.03 & 1 & .000 & 1.24 & 1.12 & 1.37 \\
\hline \multicolumn{9}{|l|}{ Block 1} \\
\hline Static-99R & .17 & .06 & 8.22 & 1 & .004 & 1.19 & 1.06 & 1.34 \\
\hline \multicolumn{9}{|l|}{ Block 2} \\
\hline Static-99R & .14 & .06 & 4.75 & 1 & .029 & 1.15 & 1.01 & 1.31 \\
\hline DRAOR Protective & -.12 & .04 & 8.94 & 1 & .003 & .89 & .82 & .96 \\
\hline \multicolumn{9}{|l|}{ Block 1} \\
\hline Static-99R & .174 & .061 & 8.220 & 1 & .004 & 1.19 & 1.06 & 1.34 \\
\hline \multicolumn{9}{|l|}{ Block 2} \\
\hline Static-99R & .09 & .06 & 2.12 & 1 & .145 & 1.10 & .97 & 1.25 \\
\hline DRAOR Total & .08 & .02 & 22.76 & 1 & .000 & 1.09 & 1.05 & 1.22 \\
\hline \multicolumn{9}{|l|}{ Block 1} \\
\hline Static-99R & .17 & .06 & 8.22 & 1 & .004 & 1.19 & 1.06 & 1.24 \\
\hline \multicolumn{9}{|l|}{ Block 2} \\
\hline Static-99R & .09 & .06 & 1.85 & 1 & .174 & 1.09 & .96 & 1.23 \\
\hline DRAOR Stable & .19 & .07 & 7.21 & 1 & .007 & 1.22 & 1.05 & 1.41 \\
\hline
\end{tabular}




\begin{tabular}{lrrrrrrrr} 
DRAOR Acute & .07 & .071 & .941 & 1 & .332 & 1.07 & .93 & 1.23 \\
DRAOR Protective & .01 & .050 & .011 & 1 & .917 & 1.01 & .91 & 1.11 \\
\hline
\end{tabular}

Moderated Cox Regression Survival Analysis. A Cox regression survival analysis was also conducted to determine if the DRAOR protective domain moderated the relationship between static risk and recidivism. That is, this analysis was undertaken to determine if higher scores on the protective domain would mitigate the impact of risk on reoffending. To test the independent effects of risk and protective factors (i.e. main effects) both factors were entered simultaneously in the first block, while the interaction term of Total Risk x Total Protective score was entered in the second block.

As Table 15 illustrates, when the main effects were entered in the first block (-2 log likelihood $=592.44), \chi^{2}(2)=17.86, p<.000$, both the Static-99R and DRAOR protective domain were significant. However, in the second block no significant interactions emerged between the protective domain and overall static risk in predicting parole failures $(-2 \log$ likelihood $=591.51), \chi^{2}(1)=17.86, p=.33$ A moderation analysis was not conducted for sexual recidivism as only the Static-99R emerged as a significant predictor for this outcome. 
Table 15.

Moderated Cox regression survival analysis

\begin{tabular}{|c|c|c|c|c|c|c|c|c|}
\hline \multirow[b]{2}{*}{ Variable } & \multirow[b]{2}{*}{$B$} & \multirow[b]{2}{*}{$S E$} & \multirow[b]{2}{*}{ Wald } & \multirow[b]{2}{*}{$d f$} & \multirow[b]{2}{*}{$p$} & \multirow[b]{2}{*}{$\operatorname{Exp}(B)$} & \multicolumn{2}{|c|}{$95 \%$ CI for $\operatorname{Exp}(B)$} \\
\hline & & & & & & & $\begin{array}{l}\text { Lower } \\
\text { Bound }\end{array}$ & $\begin{array}{l}\text { Upper } \\
\text { Bound }\end{array}$ \\
\hline \multicolumn{9}{|l|}{ Block 1} \\
\hline Total Static-99R score & .14 & .07 & 4.75 & 1 & .03 & 1.15 & 1.01 & 1.31 \\
\hline Total Protective Score & -.12 & .04 & 8.94 & 1 & .003 & .89 & .82 & .96 \\
\hline \multicolumn{9}{|l|}{ Block 2} \\
\hline Total Static-99R score & .05 & .11 & .21 & 1 & .64 & 1.05 & .85 & 1.31 \\
\hline Total Protective Score & -.17 & .06 & 7.19 & 1 & .007 & .85 & .75 & .96 \\
\hline Total Risk x Protective & .02 & .02 & .97 & 1 & .32 & 1.02 & .99 & 1.05 \\
\hline
\end{tabular}




\section{Results: Study 2}

\section{Data Screening}

Missing Values. Prior to analysis, all variables were examined for accuracy of data entry and the presence of missing values. Offenders were also excluded if they were less than 18 years old at the time of release or less than 16 years old when they committed the index offence $(n=$ 10). Further, the mean length of time between their release date and their first Stable-2007 and Acute-2007 assessment was 9.13 months $(S D=10.56)$. Cases were excluded if they recidivated before their first dynamic assessment $(n=10)$. The exclusion of these cases reduced the sample from 227 to 207 sex offenders. All subsequent analyses were conducted with this reduced sample. There was no other missing data in the variables of interest.

Distribution. All variables were examined for outliers, normality, linearity and homoscedasticity. An examination of box plots and standardized z-scores revealed that there were no univariate outliers. Normality was screened through an examination of probability plots and histograms, which revealed no visible departure from normality. In addition, the standardized values of both skewness and kurtosis did not exceed 3.29 (two-tailed) using an alpha level of .001. Homoscedasticity and linearity were examined among the variables through visual examination of bivariate scatterplots and residual plots (plots standardized predicted values against standardized residuals). Results demonstrated that all variable pairs tested in regression were linearily related. Further, no variables visibly showed clear departures from homoscedasticity.

Multivariate outliers were analyzed through Mahalanobis' distance, and influence values. Results from Mahalanobis' distance revealed that none of the cases exceeded the critical value of 
$18.47(d f=4, \alpha=.001)$. All of the DFBeta values were below 1 , indicating no multivariate outliers.

Proportional Hazards Assumption. This assumption was tested using the log minus log plots of the hazard function. This assumption was not violated as the lines were parallel and did not cross each other.

Recidivism Rates. Table 16 displays the recidivism rates for the whole sample and sex offender subgroups. The maximum follow-up period was 136 months $(M=41.98, S D=25.04)$, with $32.9 \%$ of the sample reoffending with a technical violation. As Table 16 illustrates, only $7.2 \%$ of the sample recidivated with a new sexual crime. As such, caution should be taken when examining the results, as low reconviction rates in this relapse category can result in unreliable results. None of the offender's recidiviated with a violent crime. Therefore, subsequent analyses only examined these two recidivism outcomes. The mean time to first rule violation was 34.81 months $(S D=26.83)$, whereas the mean time to first sexual recidivism was 40.11 months $(S D=$ 25.39).

Table 16

Recidivism Rates

\begin{tabular}{lccc}
\hline Recidivism Type & $\begin{array}{c}\text { Whole Sample } \\
(\mathrm{n}=207) \\
\%(\mathrm{n})\end{array}$ & $\begin{array}{c}\text { Rapists }(\mathrm{n}=79) \\
\%(\mathrm{n})\end{array}$ & $\begin{array}{c}\text { Child Molesters }(\mathrm{n}=94) \\
\%(\mathrm{n})\end{array}$ \\
\hline Parole Violations & $32.9(68)$ & $10.1(21)$ & $16.9(35)$ \\
Any Sexual Recidivism & $7.2(15)$ & $2.4(5)$ & $3.9(8)$ \\
\hline
\end{tabular}


Measures: Descriptives. Table 17 displays the descriptive statistics for each measure. In addition, independent samples $t$-tests were conducted to assess mean differences between rapists and child molesters on static risk and each of the dynamic measures. Table 18 indicates that rapists had higher mean scores on the Static-99R compared to child molesters. However, there were no significant differences on the dynamic measures.

Table 17

Descriptive Statistics for Static-99R, Stable-2007 and Acute-2007

\begin{tabular}{lccc}
\hline Measure & Mean & SD & Range \\
\hline Static-99R & 2.89 & 2.15 & $-3-9$ \\
Stable-2007 & 7.15 & 4.28 & $0-21$ \\
Acute-2007 (S/V) & .84 & 1.13 & $0-7$ \\
Acute-2007 & 1.49 & 2.89 & $0-10$ \\
\hline
\end{tabular}

Note. $\mathrm{S} / \mathrm{V}=\mathrm{sex} /$ violence subscale

Table 18

Comparisons between Rapists and Child Molesters

\begin{tabular}{lcccc}
\hline Variable & $\begin{array}{c}\text { Rapists } \\
M(S D)\end{array}$ & $\begin{array}{c}\text { Child Molesters } \\
M(S D)\end{array}$ & $t$ & $p$ \\
\hline \multicolumn{1}{c}{ Static-99R } & $\mathbf{3 . 2 3}(\mathbf{2 . 2 0})$ & $\mathbf{2 . 3 2}(\mathbf{1 . 8 1})$ & $\mathbf{- 2 . 9 3}$ & $\mathbf{. 0 0 4}$ \\
Dynamic Measures & & & & \\
Stable-2007 & $6.46(4.16)$ & $7.59(4.35)$ & 1.69 & .09 \\
Acute-2007 (S/V) & $.89(1.26)$ & $.82(1.12)$ & -.38 & .705 \\
Acute-2007 Total & $1.59(1.82)$ & $1.42(1.60)$ & -.67 & .502
\end{tabular}

Note. $\mathrm{S} / \mathrm{V}=\mathrm{sex} /$ violence subscale; Bonferroni correction of $p<05 / 4=.01$. Bold denotes significance after Bonferroni Correction. 
Comparisons between recidivists and non-recidivists. Comparisons were made

between those who recidivated and those who did not recidivate for both parole violations and sexual recidivism. Independent sample $t$-tests were used to compare scores on the Stable-2007, Acute-2007 (including the sex/violence subscale) and the Static-99R among the two groups. A Bonferroni correction was made for each t-test in order to maintain the family-wise error rate at $\alpha=.05$.

As can be seen in Table 19, those that reoffended with a parole violation had significantly higher mean scores on the Static-99R, Acute-2007 (excluding the sex/violence subscale) and the Stable-2007, compared to those that desisted. When examining sexual recidivism, a different pattern emerged. As Table 20 illustrates, no differences between recidivists and non-recidivists were found on any of the dynamic measures. However, those that desisted had significantly lower scores on the Static-99R.

Table 19

Parole Violations: Comparisons between Recidivists and Non-recidivists

\begin{tabular}{ccccc}
\hline Variable & $\begin{array}{c}\text { Recidivists } \\
M(S D)\end{array}$ & $\begin{array}{c}\text { Non-recidivists } \\
M(S D)\end{array}$ & $t$ & $p$ \\
\hline Static-99R & $\mathbf{3 . 5 6}(\mathbf{2 . 2 2})$ & $\mathbf{2 . 5 8 ( 2 . 0 6 )}$ & $\mathbf{- 2 . 9 6}$ & $\mathbf{. 0 0 3}$
\end{tabular}

Dynamic Measures

$\begin{array}{lcccr}\text { Stable-2007 } & \mathbf{8 . 2 9}(\mathbf{3 . 6 3}) & \mathbf{6 . 5 9}(\mathbf{4 . 4 7}) & \mathbf{- 2 . 5 8 4} & \mathbf{. 0 1 1} \\ \text { Acute-2007 }(\mathrm{S} / \mathrm{V}) & 1.06(1.38) & .732(.97) & 1.96 & .051 \\ & & & & \\ \text { Acute-2007 Total } & \mathbf{1 . 9 9}(\mathbf{1 . 9 9}) & \mathbf{1 . 2 5}(\mathbf{1 . 3 9}) & \mathbf{- 3 . 0 7 4} & \mathbf{. 0 0 2}\end{array}$

Note. $\mathrm{S} / \mathrm{V}=\operatorname{sex} /$ violence subscale; Bonferroni correction of $p<05 / 4=.01$. Bold denotes significance after Bonferroni Correction. 
Table 20

Sexual Recidivism: Comparisons between Recidivists and Non-recidivists

\begin{tabular}{lcccc}
\hline Variable & $\begin{array}{c}\text { Recidivists } \\
M(S D)\end{array}$ & $\begin{array}{c}\text { Non-recidivist } \\
M(S D)\end{array}$ & $t$ & $p$ \\
\hline Static-99R & $\mathbf{5 . 1 5 ( 2 . 4 4 )}$ & $\mathbf{2 . 7 3 ( 2 . 0 4 )}$ & $\mathbf{- 4 . 0 7}$ & $\mathbf{. 0 0 0}$
\end{tabular}

Dynamic Measures

Stable-2007

$8.15(2.70)$

7.07 (4.38)

$-.87$

.383

Acute-2007 (S/V)

$1.27(1.75)$

$.81(1.06)$

$-1.53$

.128

Acute-2007 Total

$2.07(2.37)$

$1.44(1.58)$

$-1.42$

.158

Note. $\mathrm{S} / \mathrm{V}=\operatorname{sex} /$ violence subscale; Bonferroni correction of $p<05 / 4=.01$. Bold denotes significance after Bonferroni Correction.

Convergent Validity. To examine convergent validity, correlational analyses were conducted between the Stable-2007, Acute-2007 (including the sex/violence subscale) and the Static-99R to determine if the dynamic measures are assessing similar items contained in the Static-99R. As can be seen in Table 21, all correlations among measures were significant at the $p$ $<.01$ level. The largest correlation observed was between the Static-99R and Stable-2007 ( $r=$ .28). Among the dynamic measures, the largest correlation was observed between the Acute2007 sex/violence subscale and the Stable-2007 $(r=.35)$. 
Table 21

Correlation Matrix

\begin{tabular}{llll}
\hline Measure & AcuteS/V & AcuteTotal & Stable-2007 \\
\hline Static-99R & $.24 * *$ & $.22 * *$ & $.28 * *$ \\
Acute $-2007(\mathrm{~S} / \mathrm{V})$ & $.79 * *$ & $.35^{* *}$ \\
Acute-2007 Total & & $.30^{* *}$ \\
\hline
\end{tabular}

Note. $\mathrm{S} / \mathrm{V}=\operatorname{sex} /$ violence subscale; $* * p<.01$.

Predictive Validity. Table 22 displays bivariate correlations (Pearson's $r$ ), Cohen's $d$, and $A U C$ values for the Static-99R, Stable-2007 and Acute-2007 (including the sex/violence subscale). Similar to Study 1, the base rate for both sexual recidivism and rule violations was below $50 \%$. ROC analyses were also conducted to examine the predictive accuracy of these measures in predicating sexual recidivism and parole violations. With the exception of the Acute-2007 sex/violence subscales, the Static-99R, the Stable-2007 and the Acute-2007 total score accurately predicted parole violations, but not sexual reoffending. In addition, there was a clear overlap in confidence intervals between the measures, indicating that most of the variation in the differences in predictive accuracy can be attributed to chance alone. 
Table 22

Predictive Accuracy (ROC)

\begin{tabular}{|c|c|c|c|c|c|c|}
\hline \multirow[b]{2}{*}{ Variable } & \multirow[b]{2}{*}{$r$} & \multirow[b]{2}{*}{$d$} & \multirow[b]{2}{*}{ AUC } & \multirow[b]{2}{*}{$S E$} & \multicolumn{2}{|c|}{ Asymptotic $95 \% \mathrm{CI}$} \\
\hline & & & & & Lower & Upper \\
\hline & \multicolumn{6}{|c|}{ Parole Violations } \\
\hline Static-99R & $.21 * *$ & .47 & $.63 * *$ & .04 & .55 & .72 \\
\hline \multicolumn{7}{|l|}{ Dynamic Measures } \\
\hline Stable-2007 & $.19 *$ & .51 & $.64 * *$ & .04 & .56 & .72 \\
\hline Acute-2007 (S/V) & .14 & .21 & .56 & .04 & .47 & .64 \\
\hline \multirow[t]{2}{*}{ Acute-2007 Total } & $.21 * *$ & .40 & $.61^{* *}$ & .04 & .52 & .69 \\
\hline & \multicolumn{6}{|c|}{ Sexual Recidivism } \\
\hline Static-99R & $.28 * *$ & .47 & .63 & .10 & .43 & .83 \\
\hline \multicolumn{7}{|l|}{ Dynamic Measures } \\
\hline Stable-2007 & .06 & .43 & .62 & .06 & .49 & .74 \\
\hline Acute-2007 (S/V) & .11 & .32 & .59 & .08 & .44 & .74 \\
\hline Acute-2007 Total & .10 & .36 & .60 & .07 & .47 & .74 \\
\hline
\end{tabular}

Note. $\mathrm{S} / \mathrm{V}=\mathrm{sex} /$ violence subscale; $\mathrm{AUC}=$ area under the curve; $\mathrm{SE}=$ standard error; $\mathrm{CI}=$ confidence interval. $* p<.05 . * * p<.01 . * * * p<.001$.

\section{Cox Regression survival analysis}

Univariate Results. Four cox regression survival analyses were individually conducted with the Static-99R total score and each of the dynamic measures to identify which variables were independently related to survival time. Results varied depending on the recidivism criteria. As seen in table 23, only the Static-99R significantly predicted time until sexual recidivism (-2 $\log$ likelihood $=110.16), \chi^{2}(1)=16.49, p=.000$, indicating that having a higher score on this domain was related to a decrease in survival time, with every unit increase in the total score yielding a $65 \%$ increase in risk of sexual reoffending. In contrast, the Stable-2007 (-2 log likelihood $=579.107), \chi^{2}(1)=8.51, p=.004$, the Acute-2007 sex/violence subscale $(-2 \log$ 
likelihood $=655.88), \chi^{2}(1)=5.63, p=.02$, the Acute-2007 total score $(-2$ log likelihood $=$ 649.77); $\chi^{2}(1)=11.746, p=.001$, and the Static-99R $(-2 \log$ likelihood $=585.239), \chi^{2}(1)=$ $9.660, p=.002$, all significantly predicted rule violations. Further, the regression coefficients for all the measures were positive, indicating that those offenders with higher risk scores failed at a faster rate than those with lower scores. Table 24 displays the results for parole violations.

Table 23

Cox Regression Survival Analysis Predicting Sexual Recidivism: Univariate Analysis

\begin{tabular}{lcccccccc}
\hline & & & & & & & \multicolumn{3}{c}{$95 \%$ CI for $\operatorname{Exp}(B)$} \\
\cline { 3 - 8 } Variable & $B$ & $S E$ & Wald & $d f$ & $p$ & $\operatorname{Exp}(B)$ & $\begin{array}{c}\text { Lower } \\
\text { Bound }\end{array}$ & Uound \\
\hline Static-99R & .51 & .12 & 16.73 & 1 & .000 & 1.69 & 1.30 & 2.11 \\
Dynamic Measures & & & & & & & & \\
Stable-2007 & .07 & .059 & 1.37 & 1 & .24 & 1.07 & .95 & 1.20 \\
Acute-2007 (S/V) & .28 & .16 & 2.92 & 1 & .09 & 1.32 & .96 & 1.81 \\
Acute-2007 Total & .21 & .12 & 3.11 & 1 & .08 & 1.23 & .98 & 1.55 \\
\hline
\end{tabular}

Note. $\mathrm{S} / \mathrm{V}=$ sex/violence subscale.

Table 24

Cox Regression Survival Analysis Predicting Parole Violation: Univariate Analyses

\begin{tabular}{|c|c|c|c|c|c|c|c|c|}
\hline & \multirow[b]{2}{*}{$B$} & \multirow[b]{2}{*}{$S E$} & \multirow[b]{2}{*}{ Wald } & \multirow[b]{2}{*}{$d f$} & \multirow[b]{2}{*}{$p$} & \multirow[b]{2}{*}{$\operatorname{Exp}(B)$} & \multicolumn{2}{|c|}{$95 \%$ CI for $\operatorname{Exp}(B)$} \\
\hline & & & & & & & $\begin{array}{l}\text { Lower } \\
\text { Bound }\end{array}$ & $\begin{array}{l}\text { Upper } \\
\text { Bound }\end{array}$ \\
\hline Static-99R & .18 & .06 & 10.13 & 1 & .001 & 1.20 & 1.07 & 1.35 \\
\hline \multicolumn{9}{|l|}{ Dynamic Measures } \\
\hline Stable-2007 & .08 & .03 & 9.16 & 1 & .002 & 1.09 & 1.03 & 1.14 \\
\hline Acute-2007 (S/V) & .23 & .09 & 6.91 & 1 & .009 & 1.26 & 1.06 & 1.49 \\
\hline Acute-2007 Total & .22 & .06 & 15.24 & 1 & .000 & 1.24 & 1.11 & 1.38 \\
\hline
\end{tabular}


Multivariate Results. All static and dynamic variables that were found to be individually related to survival time were retained for subsequent analyses. Since only the Static-99R yielded a significant result when predicting time to sexual recidivism, only parole violations were examined. To examine the incremental validity of the dynamic variables over and above static risk, a series of hierarchal cox regression analyses was computed. In each of the models, the Static-99R was entered first in the first block, with each dynamic variable entered in the second block to determine if the dynamic predictors contributed unique variance in the outcome while controlling for static risk. In a final model, the Static-99R was entered in the first block, with the Stable-2007 and Acute-2007 (including the sex/violence subscale) entered simultaneously in the second block.

For the first comparison, when the Static-99R scores were entered in the first block, the overall model was significant $(-2 \log$ likelihood $\left.=555.749), \chi^{2}(1)=7.748 p=.005\right)$. Adding the Stable-2007 after accounting for static risk significantly improved the predictive accuracy of the model $(-2 \log$ likelihood $=550.67), \chi^{2}$ change $\left.(1)=5.08, p=.024\right)$. Table 25 reveals that the Static-99R and Stable- 2007 each added incrementally to one another. In the next model, Static99R scores were again entered in the first step $(-2 \log$ likelihood $=575.27) \chi^{2}(1)=9.13 p=.003$, with Acute-2007 sex/violence subscale scores entered in the second block $(-2$ log likelihood $=$ 571.46), $\chi^{2}$ change $(1)=3.81, p=.041$. This significantly improved the predictive accuracy of the model, with both Static-99R scores and Acute-2007 sex/violence subscale scores each adding incrementally to one another. In Model 3, Static-99R scores were entered in the first step (-2 log likelihood $=575.27) \chi^{2}(1)=9.13 p=.003$. Adding the Acute-2007 total score after adjusting for static risk significantly improved the predictive accuracy of the model $(-2 \log$ likelihood $=$ 
567.35), $\chi^{2}$ change $(1)=7.90 p=.005$. Consistent with the previous models, both Static-99R scores and Actue-2007 total scores emerged as significant predictors.

For the final model, Static-99R scores were again entered in the first step (-2 log likelihood $\left.=545.86), \chi^{2}(1)=7.27 p=.007\right)$, with the Stable-2007, Acute-2007 sex/violence subscale and Acute-2007 total scores entered simultaneously in the second block (-2 log likelihood $=573.85), \chi^{2}$ change $(3)=8.01, p=.046$. Although the results show that as a set, the covariates significantly predicted survival time, the Stable-2007 was the only dynamic measure that emerged as a significant predictor, whereas the rest of the covariates failed to reach statistical significance. 
Table 25

Cox Regression Survival Analysis Predicting Parole Violations: Multivariate Analysis

\begin{tabular}{|c|c|c|c|c|c|c|c|c|}
\hline \multirow{2}{*}{ Variable } & \multirow{2}{*}{$B$} & \multirow{2}{*}{$S E$} & \multirow{2}{*}{ Wald } & \multirow[b]{2}{*}{$d f$} & \multirow{2}{*}{$p$} & \multirow{2}{*}{$\operatorname{Exp}(B)$} & \multicolumn{2}{|c|}{$95 \%$ CI for $\operatorname{Exp}(B)$} \\
\hline & & & & & & & $\begin{array}{l}\text { Lower } \\
\text { Bound }\end{array}$ & $\begin{array}{l}\text { Upper } \\
\text { Bound }\end{array}$ \\
\hline \multicolumn{9}{|l|}{ Block 1} \\
\hline Static-99R & .17 & .06 & 8.06 & 1 & .01 & 1.18 & 1.05 & 1.32 \\
\hline \multicolumn{9}{|l|}{ Block 2} \\
\hline Static-99R & .13 & .06 & 4.06 & 1 & .04 & 1.13 & 1.00 & 1.28 \\
\hline Stable-2007 & .07 & .03 & 5.43 & 1 & .02 & 1.07 & 1.01 & 1.13 \\
\hline \multicolumn{9}{|l|}{ Block 1} \\
\hline Static-99R & .18 & .09 & 9.57 & 1 & .00 & 1.19 & 1.07 & 1.34 \\
\hline \multicolumn{9}{|l|}{ Block 2} \\
\hline Static-99R & .15 & .06 & 5.83 & 1 & .02 & 1.16 & 1.03 & 1.31 \\
\hline Acute-2007 (S/V) & .19 & .09 & 4.47 & 1 & .04 & 1.22 & 1.01 & 1.46 \\
\hline \multicolumn{9}{|l|}{ Block 1} \\
\hline Static-99R & .18 & .06 & 9.57 & 1 & .00 & 1.19 & 1.07 & 1.34 \\
\hline \multicolumn{9}{|l|}{ Block 2} \\
\hline Static-99R & .14 & .06 & 5.25 & 1 & .02 & 1.15 & 1.02 & 1.31 \\
\hline Acute-2007 Total & .18 & .06 & 9.68 & 1 & .00 & 1.20 & 1.07 & 1.35 \\
\hline \multicolumn{9}{|l|}{ Block 1} \\
\hline Static-99R & .16 & .06 & 7.57 & 1 & .01 & 1.18 & 1.05 & 1.32 \\
\hline \multicolumn{9}{|l|}{ Block 2} \\
\hline Static-99R & .11 & .07 & 3.04 & 1 & .08 & 1.121 & .99 & 1.27 \\
\hline Stable-2007 & .05 & .03 & 3.71 & 1 & .04 & 1.06 & .99 & 1.13 \\
\hline Acute-2007 (S/V) & .13 & .17 & .60 & 1 & .44 & .88 & .63 & 1.22 \\
\hline Acute-2007 Total & .19 & .11 & 3.08 & 1 & .08 & 1.22 & .98 & 1.52 \\
\hline
\end{tabular}




\section{Discussion}

The objective of the current study was to examine three main research areas. First, this study explored whether there were meaningful differences among static and dynamic risk assessment instruments in their level of predictive accuracy for both sexual recidivism and technical violations. The second objective involved examining the incremental contribution of the dynamic measures in predicting sexual and technical violations over and above static estimates. Third, an exploration of the relationship between risk and protective factors in relation to recidivism was also undertaken. An overview of the findings for each study is reviewed below.

\section{Overview of Findings: Study 1}

Convergent validity. The first part of the current study involved examining convergent validity between the DRAOR and Static-99R. This was undertaken by computing correlation coefficients between the DRAOR and the Static-99R, which is a well validated measure of sexual recidivism. Previous research has demonstrated that measures of static risk are correlated with measures of dynamic risk (Wong \& Gordon, 2006). Results demonstrated that all of the correlations were significant and in the expected direction. That is, the DRAOR risk domains and total score were positively correlated with the Static-99R. In addition, consistent with previous research (Tamatea \& Wilson, 2009), the DRAOR protective domain demonstrated an inverse relationship with the static variable and the DRAOR risk domains, indicating that higher scores on the protective domain were associated with lower static and dynamic risk scores. This further demonstrates that the protective variables "may utilise different psychological processes than risk" (p.4; Tamatea \& Wilson, 2009). It is important to note, that the correlations between the DRAOR domains and Static-99R did not exceeded .26 (including the protective domain), 
suggesting that the DRAOR subscales and overall score may not be assessing the same constructs as assessed by the Static-99R.

Although not a direct hypothesis in the current study, comparisons between recidivists and non-recidivists on key indicators revealed significant differences. The independent sample ttests for both samples, demonstrated that those who recidiviated during the follow-up period, had significantly higher mean scores on the Static-99R and DRAOR subscales and overall score. However, results varied depending on the recidivism criteria. Those that recidiviated with a technical violation had significantly higher scores on the DRAOR total score and on the stable, acute domains, with lower scores on the Protective domain. When examining sexual recidivism, recidivists scored significantly higher on the Static-99R than non-recidivists. However, there was no significant difference among those that recidiviated and those that desisted on the DRAOR subscales and overall scores. This lack of significant differences on these indicators is likely due to the low base rates observed on this recidivism criteria.

Predictive accuracy. Utilizing ROC procedures as an index of predictive validity, the predictive accuracy of the DRAOR was examined to determine if this measure would be able to predict both parole and sexual failures. When examining parole violations as the outcome criteria, AUCs were significant for each DRAOR subscale and total score as well as the Static99R. Due to the clear overlap in confidence intervals between the DRAOR and Static-99R, these results indicate that none of the subscales or total score showed any difference in predictive accuracy; suggesting they are performing equivalently, with no clear superiority in predictive accuracy compared to the Static-99R. However, when examining sexual recidivism as the outcome criteria, only the Static-99R demonstrated significant predictive accuracy. However, due to the extremely low base rates of this outcome, results should be interpreted with caution. 
Incremental Validity. By utilizing cox regression survival analyses, both univariate and multivariate analyses were employed. At the univariate level, the Static-99R scores and DRAOR subscales and total scores significantly predicted time until parole failures. However, these results were not observed when predicting time to sexual recidivism. Only the Static-99R significantly predicted time until sexual recidivism. In order to examine the incremental contribution of the DRAOR over and above static estimates, a series of hierarchal cox regression survival analyses was computed. At the multivariate level, the DRAOR total score and subscales incrementally predicted rule violations over and above static estimates.

Moderation. The results of the moderation analysis demonstrated that protective scores did not appear to ameliorate the risk for future reoffending. However, the protective domain demonstrated a main effect. That is, the protective domain revealed independent effects irrespective of static risk. These results are consistent with previous research examining the interaction between risk and protective factors. For instance, previous research conducted with young offenders (Hoge et al., 1996) and adult offenders (Ullrich \& Coid, 2011), found that none of the interactions of risk and protective factors emerged as statistically significant, but instead found that protective factors yielded a significant independent effect.

\section{Overview of Findings: Study 2}

Convergent validity. Correlational analyses between the dynamic measures and the Static-99R were also examined. All of the correlations were significant at the $p<.05$ level and in the expected direction, with the Stable-2007, Acute-2007 and Static-99R all demonstrating positive relationships. Again, the largest correlation observed was .28, further indicating that the dynamic measures in this sample may be assessing different constructs than the Static-99R. Further, both the Acute-2007 and Stable-2007 demonstrated a moderate association. 
Predictive accuracy. The predictive accuracy for the Stable-2007 and Acute-2007 was similar to those found with the DRAOR sample. With the exception of the Acute-2007 sex/violence subscale, the Stable-2007, Acute-2007 total score and Static-99R all signficicantly predicted rule violations. However, due to the considerable overlap in confidence intervals between the measures, most of the variation in the differences in predictive accuracy can be attributed to chance alone. In addition, none of the risk measures were able to predict sexual recidivism. The lack of predictive accuracy in predicting new charges is again likely due to extremely low base rates.

Incremental Validity. Both univariate and multivariate cox regression survival analyses were examined for the Stable-2007, Acute-2007 and the Static-99R. At the univariate level, the Static-99R scores and both dynamic measures predicted time until parole failures. However, these results were not observed when predicting time until sexual recidivism. Again only the Static-99R significantly predicted time until sexual recidivism. A series of hierarchal cox regression survival analyses were also computed to examine the incremental contribution of dynamic measures over static estimates. Both dynamic measures made a significant contribution to the prediction of parole failures over and above the Static-99R. A final model was computed with Static-99R scores entered in the first block, followed by the Stable-2007 and Acute-2007 entered simultaneously in the second block. Although the overall model was significant, only the Stable-2007 accounted for unique variance in predicting parole failures.

\section{Limitations}

The results of the current study should be considered in light of some limitations. Due to low prevalence rates for sexual recidivism observed in both samples, the ability to find significant results was reduced. When examining predictive accuracy utilizing ROC analyses, none of the dynamic measures was able to significantly predict sexual recidivism. At the 
univariate level, none of the dynamic measures was related to survival time. Consequently, examining the incremental contribution of dynamic variables over and above static risk estimates was not possible.

One possible explanation for the low base rates may be related to the intensive community supervision approaches commonly applied to sex offenders, regardless of their level of static risk. Highly intensive and punitive community supervision approaches, which tend to monitor compliance (Yesberg et al., 2013), may lead to higher rates of revocation for technical breaches (Helmus, 2009), With intensive supervision programs (ISP), which include electronic monitoring, curfews, day reporting centers and house arrest, emphasis is commonly placed on detecting violations (Lowenkamp, Flores, Holsinger, Makarios, \& Latessa, 2010). In fact, Petersilia and Turner (1993) found that offenders placed in ISP programs experienced 27 percent more violations than those placed on traditional parole. From a methodological standpoint, this may artificially reduce base rates for more serious recidivism outcomes as this may limit the opportunity to commit a new offense (Helmus, 2009). However, community supervision approaches are slowly beginning to focus on a hybrid model, which combines the compliance model with Core Correctional Practice (Bonta, Bourgon, Rugge, Scott, Yessine, Gutierrez, \& Li, 2001; Yesberg et al., 2013). Essentially, this model views community supervision as a form of intervention, where adherence to the RNR principles may be related to improved outcomes, (Yesberg et al, 2013).

Since the data in the current study was archival, interrater reliability could not be assessed for the dynamic measures. As these dynamic measures rely on parole officer's ratings of risk, unreliability of officer ratings, as well as rater drift, is a concern. Relatedly, another consideration is the importance of implementation integrity, which is commonly measured 
through staff training and the amount of time using the tool (Flores, Lowenkamp, Holsinger, \& Latessa, 2006). Evaluation of the predictive validity of risk assessment tools is based on the premise that they have been implemented properly, such that staff has been properly and sufficiently trained. Previous research has demonstrated the importance of implementation integrity in relation to predictive validity (Flores et al., 2006) and also the importance of ongoing training and support in reducing prediction errors (Bonta, Bogue, Crowley, \& Motiuk, 2001). That is, the accuracy of the information used to complete the assessment ultimately rests on the evaluator. Hanson et al. (2007) demonstrated a difference in predictive accuracy between conscientious officers and non-conscientious officers. When examining the Stable-2007 and Acute-2007, Hanson et al. (2007) found differences in predicative accuracy among conscientious officers compared to the complete sample of all the officers (ROCs of .77 and .67, respectively). The ability to reliably differentiate higher risk offenders from lower risk offenders has important implications for effective programming, as well as public safety.

Another limitation has to do with the time between release and the first dynamic assessment. For instance, the average length of time between release and the first DRAOR assessment was 7 months, whereas the length of time between release and the first Stable-2007 and Acute-2007 assessment was 9 months. Generally, increased recidivism rates are often observed within the first few weeks and months after release into the community, as offenders are often faced with changing circumstance and may fail to successfully adjust to these changes. (Yesberg et al., 2009).

\section{Implications and Directions for Future Research}

Although there were no a priori hypotheses regarding differences among subgroups of offenders, the results of the independent sample t-tests revealed that rapists had significantly 
higher mean scores on the Static-99R compared to child molesters. However, differences on the DRAOR subscales and total score failed to demonstrate significant differences between these two groups. A similar pattern emerged when examining differences between these groups with Study 2. Rapists had significantly higher scores on the Static-99R compared to child molesters, but no significant differences were found on the Stable-2007 and the Acute-2007 (including the sex/violence subscale). Research should continue to investigate differences among sex offenders as previous research has demonstrated that these sex offender types differ on many relevant dynamic domains.

Although not addressed in this study, the extant literature has demonstrated that this heterogeneity among sex offenders also affects the predictive accuracy of risk assessment instruments, such that failing to consider sex offender typologies may impair predictive validity estimates (Harris et al., 2003; Rattenberger et al., 2010). Although Hanson and Thornton (2000) reported similar predictive accuracy rates for both rapists and child molesters, other research has consistently shown differences in predictive accuracy among subgroups of offenders (Bartosh et al., 2003; Eher et al., 2010; Harris et al., 2003; Rattenberger et al., 2010) For instance, in a study conducted by Harris et al. (2003), they compared the predictive accuracy of four actuarial risk scales in predicting violent and sexual recidivism and examined the performance of these instruments for rapists and child molesters separately. Results demonstrated that the predictive accuracy was higher for child molesters $(A U C=.65)$ compared to rapists $(A U C=.59$; Harris et al., 2003). In addition, both Bartosh et al. (2003) and Eher et al. (2008) demonstrated that the predictive accuracy for sexual relapse was higher for child molesters than rapists.

Investigating the extent to which dynamic risk assessment information is used in developing case management strategies is an area of research that warrants further investigation. 
Utilizing dynamic risk assessment information may lead to more case specific decision-making. Ongoing assessment of dynamic factors during community supervision may inform parole and probation officers when an offender is at risk to reoffend, which can guide intervention strategies to mitigate risk, and improve individual case planning. This further highlights the importance of assessing changes on dynamic risk variables, particularly acute factors, which may signal the imminence of reoffending. However, monitoring change should not be restricted to risk factors, as protective factors are also dynamic in nature. Instead, a balanced approach to risk management should be employed as this may shift the emphasis from risk avoidance to a focus on crime desistance (Yesberg et al., 2013). Therefore, this change in supervision strategies may help cultivate offender assets and maintain motivation to change.

Although static risk estimates provide criminal justice personnel information regarding which offenders are high risk, these factors do not provide practical guidelines to aide with individual, case base-decisions in order to enhance community supervision practices. All of the dynamic measures included in this study were designed to monitor and assess changes in risk. However, the current study only assessed the dynamic measures at one time point. Although examining changes on the dynamic variables was beyond the scope of the current study, research should continue to examine variability in dynamic risk and protective scores over time and whether changes on these variables are related to differential outcome for sex offenders and other relevant offender populations. With regards to protective factors, the results of this study indicate the importance and clinical utility of protective factors in predicting parole failures. Further, the DRAOR protective domain had an impact on recidivism, irrespective of if the offender was high, medium or low risk. This finding has implications for probation officers as they can target these strength factors for intervention and case planning. However, research on 
the relationship between protective factors and recidivism is still in its infancy. Considering a range of internal and external attributes that may reduce offenders' risk of reoffending may provide useful information regarding the transition into desistance. 


\section{References}

Abracen, J., Mailloux, D. L., Serin, R. C., Cousineau, C., Malcolm, P. B., \& Looman, J. (2004). A model for the assessment of static and dynamic factors in sexual offenders. Journal of Sex Research, 41(4), 321-328. doi. 10.1080/00224490409552239

Allan, M., Grace, R. C., Rutherford, B., \& Hudson, S. M. (2007). Psychometric assessment of dynamic risk factors for child molesters. Sexual Abuse: A Journal of Research and Treatment, 19(4), 347-367.

Andrews, D. A., \& Bonta, J. (2010). The psychology of criminal conduct $\left(5^{\text {th }} \mathrm{ed}\right.$.). Cincinnati, $\mathrm{OH}, \mathrm{US}$ : Anderson Publishing Co.

Andrews, D. A., Bonta, J., \& Wormith, J. S. (2006). The recent past and near future of risk and/or need assessment. Crime and Delinquency, 52(1), 7. doi. $10.1177 / 0011128705281756$

Babchishin, K. M., Hanson, R. K., \& Helmus, L. (2011). The RRASOR, Static-99R, and Static 2002R all add incrementally to the prediction of recidivism among sex offenders (Corrections Research User Report No. 2011-02). Ottawa, ON: Public Safety Canada.

Barbaree, H. E. (1991). Denial and minimization among sex offenders: Assessment and treatment outcomes. Forum on Corrections Research, 3, 30-33.

Barbaree, H. E., Seto, M. C., Langton, C. M., \& Peacock, E. J. (2001). Evaluating the predictive accuracy of six risk assessment instruments for adult sex offenders. Criminal Justice and Behavior, 28(4), 490-521. doi. 10.1177/009385480102800406

Barnett, G. D., Wakeling, H., Mandeville-Norden, R., \& Rakestrow, J. (2013). Does change in psychometric test scores tell us anything about risk of reconviction in sexual offenders? Psychology, Crime \& Law, 19(1), 85-110.

Bartosh, D. L., Garby, T., Lewis, D., \& Gray, S. (2003). Differences in the predictive validity of actuarial risk assessments in relation to sex offender type. International Journal of Offender Therapy and Comparative Criminology, 47(4), 422-438. doi. 10.1177/0306624X03253850

Bonta, J. (1996). Risk-needs assessment and treatment. In A. T. Harland (Ed.), Choosing correctional options that work: Defining the demand and evaluating the supply (pp. 18-32). Thousand Oaks, CA: Sage.

Bonta, J., Bogue, B., Crowley, M., \& Motiuk, L. (2001). Implementing offender classification systems: Lessons learned. Offender rehabilitation in practice: Implementing and evaluating effective programs, 227-245. 
Bonta, J., Bourgon, G., Rugge, T., Scott, T. L., Yessine, A. K., Gutierrez, L., \& Li, J. (2011). An experimental demonstration of training probation officers in evidence-based community supervision. Criminal justice and behavior, 38(11), 1127-1148. doi.

$10.1177 / 0093854811420678$

Beech, A. R. (1998). A psychometric typology of child abusers. International Journal of Offender Therapy and Comparative Criminology, 42(4), 319-339. doi. 10.1177/0306624X9804200405

Beech, A. R., Fisher, D. D., \& Thornton, D. (2003). Risk assessment of sex offenders. Professional Psychology: Research and Practice, 34(4), 339-352. doi. 10.1037/07357028.34.4.339

Beech, A., Friendship, C., Erikson, M., \& Hanson, R. K. (2002). The relationship between static and dynamic risk factors and reconviction in a sample of UK child abusers. Sexual Abuse: A journal of research and treatment, 14(2), 155-167.

Beech, A. R., \& Ward, T. (2004). The integration of etiology and risk in sexual offenders: A theoretical framework. Aggression and Violent Behavior, 10(1), 31-63. doi.10.1016/j.avb.2003.08.002

Beggs, S. M., \& Grace, R. C. (2011). Treatment gain for sexual offenders against children predicts reduced recidivism: a comparative validity study. Journal of consulting and clinical psychology, 79(2), 182.

Borowsky, I. W., Hogan, M., \& Ireland, M. (1997). Adolescent sexual aggression: risk and protective factors. Pediatrics, 100(6), e7-e7. doi. 10.1542/peds.100.6.e7

Brown, S. L., St. Amand, M. D., \& Zamble, E. (2009). The dynamic prediction of criminal recidivism: A three-wave prospective study. Law and human behavior, 33(1), 25-45. doi. 10.1007/s10979-008-9139-7

Cohen, J., Cohen, P., \& Stephen, G. West, and Leona S. Aiken. 2003. Applied multiple regression/correlation analysis for the behavioral sciences.

Cooke, D. J., \& Michie, C. (2010). Limitations of Diagnostic Precision and Predictive Utility in the Individual Case. Law and human behavior, 34(4), 259-274. doi. 10.1007/s10979-009 9176-x

Cortoni, F., \& Marshall, W. L. (2001). Sex as a coping strategy and its relationship to juvenile sexual history and intimacy in sexual offenders. Sexual Abuse: A Journal of Research and Treatment, 13(1), 27-43. doi.

Costa, F. M., Jessor, R., \& Turbin, M. S. (1999). Transition into adolescent problem drinking: The role of psychosocial risk and protective factors. Journal of Studies on Alcohol, 60(4), 480-490. doi. 
Craig, L. A., \& Beech, A. (2009). Best practice in conducting actuarial risk assessments with adult sexual offenders. Journal of Sexual Aggression, 15(2), 193-211. doi. $10.1080 / 13552600902867847$

Craig, L. A., Thornton, D., Beech, A., \& Browne, K. D. (2007). The relationship of statistical and psychological risk markers to sexual reconviction in child molesters. Criminal Justice and Behavior, 34(3), 314-329. doi. 10.1177/0093854806291416

Douglas, K. S., \& Kropp, P. R. (2002). A Prevention-Based Paradigm for Violence Risk Assessment Clinical and Research Applications. Criminal Justice and Behavior, 29(5), 617 658. doi. 10.1177/009385402236735

Douglas, K. S., \& Skeem, J. L. (2005). Violence risk assessment: Getting specific about being dynamic. Psychology, Public Policy, and Law, 11(3), 347-383.

Eher, R., Rettenberger, M., Schilling, F., \& Pfafflin, F. (2008). Failure of Static-99 and SORAG to predict relevant reoffense categories in relevant sexual offender subtypes: A prospective study. Sexual Offender Treatment, 8(1), 1-20.

Fitzpatrick, K. M. (1997). Fighting among America's youth: a risk and protective factors approach. Journal of Health and Social Behavior, 131-148. doi. 10.2307/2955421

Flores, A. W., Lowenkamp, C. T., Holsinger, A. M., \& Latessa, E. J. (2006). Predicting outcome with the Level of Service Inventory-Revised: The importance of implementation integrity. Journal of Criminal Justice, 34(5), 523-529. doi. 10.1016/j.jcrimjus.2006.09.007

Gannon, T. A. (2009). Social cognition in violent and sexual offending: an overview. Psychology, Crime \& Law, 15(2-3), 97-118. doi. 10.1080/10683160802190822

Gendreau, P., Little, T., \& Goggin, C. (1996). A meta-analysis of the predictors of adult offender recidivism: What works! Criminology, 34, 575-607. doi. 10.1111/j.1745 9125.1996.tb01220.x

HaggÅrd, U., Gumpert, C. H., \& Grann, M. (2001). Against all odds: A qualitative follow-up of high-risk violent offenders who were not reconvicted. Journal of Interpersonal Violence, 16, 1048-1065. doi. 10.1177/088626001016010005

Hanson, R. K. (1998). What do we know about sex offender risk assessment? Psychology, Public Policy, and Law, 4(1-2), 50-72. doi. 10.1037/1076-8971.4.1-2.50

Hanson, R. K., \& Bussière, M. T. (1998). Predicting relapse: A meta-analysis of sexual offender recidivism studies. Journal of Consulting and Clinical Psychology, 66(2), 348-362. doi: 10.1037/0022-006X.66.2.348 
Hanson, R. K., \& Harris, A. J. R. (2000). Where should we intervene?: Dynamic predictors of sexual assault recidivism. Criminal Justice and Behavior, 27(1), 6-35. doi. $10.1177 / 0093854800027001002$

Hanson, R. K., \& Harris, A. J. R. (2001). A structured approach to evaluating change among sexual offenders. Sexual Abuse: Journal of Research and Treatment, 13(2), 105-122.

Hanson, R. K., Harris, A. J., Scott, T., \& Helmus, L. (2007). Assessing the risk of sexual offenders on community supervision: The Dynamic Supervision Project (Vol. 5). Ottawa, Ontario, Canada: Public Safety Canada.

Hanson, R. K., Helmus, L., \& Thornton, D. (2010). Predicting recidivism amongst sexual offenders: a multi-site study of static-2002. Law and Human Behavior; Law and Human Behavior, 34(3), 198. doi. doi.org/10.1007/s10979-009-9180-1

Hanson, R. K., \& Howard, P. D. (2010). Individual confidence intervals do not inform decision makers about the accuracy of risk assessment evaluations. Law and human behavior, 34(4), 275-281. doi. doi.org/10.1007/s10979-010-9227-3

Hanson, R. K., \& Morton-Bourgon, K. E. (2004). Predictors of sexual recidivism: An updated meta-analysis. (Research Rep. No. 2004 - 02). Ottawa, Canada: Public Safety and Emergency Preparedness Canada.

Hanson, R. K., \& Morton-Bourgon, K. E. (2005). The characteristics of persistent sexual offenders: A meta-analysis of recidivism studies. Journal of Consulting and Clinical Psychology, 73(6), 1154-1163. doi: 10.1037/0022-006X.73.6.1154

Hanson, R. K., \& Morton-Bourgon, K. E. (2007). The accuracy of recidivism risk assessment for sexual offenders: A meta-analysis (User Report No. 2007-01). Ottawa, Ontario: Public Safety and Emergency Preparedness Canada.

Hanson, R. K., \& Morton-Bourgon, K. E. (2009). The accuracy of recidivism risk assessments for sexual offenders: A meta-analysis of 118 prediction studies. Psychological Assessment, 21(1), 1-21. doi. doi.org/10.1037/a0014421

Hanson, R., Morton, K. E., \& Harris, A. J. R. (2003). Sexual offender recidivism risk. Annals of the New York Academy of Sciences, 989(1), 154-166. doi. 10.1111/j.1749 6632.2003.tb07303.x

Hanson, R. K., \& Thornton, D. (2000). Improving risk assessments for sex offenders: A comparison of three actuarial scales. Law and Human Behavior, 24(1), 119-136. doi. 10.1023/A:1005482921333

Harris, A. J. R., \& Hanson, R. K. (2010). Clinical, actuarial and dynamic risk assessment of sexual offenders: Why do things keep changing?. Journal of Sexual Aggression, 16(3), 296-310. doi. 10.1080/13552600.2010.494772 
Harris, G. T., \& Rice, M. E. (2003). Actuarial assessment of risk among sex offenders. Annals of the New York Academy of Sciences, 989(1), 198-210. doi. 10.1111/j.1749 6632.2003.tb07306.x

Harris, G. T., \& Rice, M. E. (2007). Characterizing the value of actuarial violence risk assessments. Criminal Justice and Behavior, 34(12), 1638-1658. doi. $0.1177 / 0093854807307029$

Harris, G. T., Rice, M. E., Quinsey, V. L., Lalumière, M. L., Boer, D., \& Lang, C. (2003). A multisite comparison of actuarial risk instruments for sex offenders. Psychological Assessment, 15(3), 413. doi. 10.1037/1040-3590.15.3.413

Hart, S. D., \& Cooke, D. J. (2013). Another Look at the (Im-) Precision of Individual Risk Estimates Made Using Actuarial Risk Assessment Instruments. Behavioral sciences \& the law. doi. doi.org/10.1002/bs1.2049

Hart, S. D., Michie, C., \& Cooke, D. J. (2007). Precision of actuarial risk assessment instruments Evaluating themargins of error'of group v. individual predictions of violence. The British Journal of Psychiatry, 190(49), s60-s65. doi. doi.org/10.1192/bjp.190.5.s60

Helmus, L., Thornton, D., Hanson, R. K., \& Babchishin, K. M. (2012). Improving the Predictive Accuracy of Static-99 and Static-2002 With Older Sex Offenders Revised Age Weights. Sexual Abuse: A Journal of Research and Treatment, 24(1), 64-101. doi.

Hawkins, J. D., Catalano, R. F., \& Miller, J. Y. (1992). Risk and protective factors for alcohol and other drug problems in adolescence and early adulthood: Implications for substance abuse prevention. Psychological Bulletin, 112(1), 64-105. doi:10.1037/0033-2909.112.1.64

Helmus, L. (2009). Re-norming Static-99 recidivism estimates: Exploring base rate variability across sex offender samples (Master's thesis).

Hoge, R. D., Andrews, D. A., \& Leschied, A. W. (1996). An investigation of risk and protective factors in a sample of youthful offenders. Journal of Child Psychology and Psychiatry, 37(4), 419-424. doi. 10.1111/j.1469-7610.1996.tb01422.x

Johnston, L., \& Ward, T. (1996). Social cognition and sexual offending: A theoretical framework. Sexual Abuse: A Journal of Research and Treatment, 8(1), 55-80. doi.

Knight, R. A., \& Thornton, D. (2007). Evaluating and improving risk assessment schemes for sexual recidivism: A long-term follow-up of convicted sexual offenders (p. 155). National Criminal Justice Reference Service. doi.

Kraemer, H. C., Kazdin, A. E., Offord, D. R., Kessler, R. C., Jensen, P. S., \& Kupfer, D. J. (1997). Coming to terms with the terms of risk. Archives of General Psychiatry, 54(4), 337. doi. 10.1001/archpsyc.1997.01830160065009 
Kroner, D. G., Mills, J. F., \& Reddon, J. R. (2005). A coffee can, factor analysis, and prediction of antisocial behavior: The structure of criminal risk. International journal of law and psychiatry, 28(4), 360-374. doi. org/10.1016/j.ijlp.2004.01.011

Kroner, D. G., Mills, J. F., Reitzel, L. R., Dow, E., Aufderheide, D. H., \& Railey, M. G. (2007). Directions for violence and sexual risk assessment in correctional psychology. Criminal Justice and Behavior, 34(7), 906-918. doi. 10.1177/0093854807301559

Lowenkamp, C. T., Flores, A. W., Holsinger, A. M., Makarios, M. D., \& Latessa, E. J. (2010). Intensive supervision programs: Does program philosophy and the principles of effective intervention matter?. Journal of Criminal Justice, 38(4), 368-375. doi. 10.1016/j.jcrimjus.2010.04.004

McKibben, A., Proulx, J., \& Lusignan, R. (1994). Relationships between conflict, affect and deviant sexual behaviors in rapists and pedophiles. Behaviour Research and Therapy, 32(5), 571-575. doi. 10.1016/0005-7967(94)90147-3

Meehl, P. E. (1954). Clinical versus statistical prediction: A theoretical analysis and a review of the evidence. doi: 10.1037/11281-000

Miller, H. A. (2006). A dynamic assessment of offender risk, needs, and strengths in a sample of pre-release general offenders. Behavioral sciences \& the law, 24(6), 767-782. doi. $10.1002 / \mathrm{bsl} .728$

Milner, R. J., \& Webster, S. D. (2005). Identifying schemas in child molesters, rapists, and violent offenders. Sexual Abuse: A Journal of Research and Treatment, 17(4), 425-439.

Olver, M. E., Wong, S. C., Nicholaichuk, T., \& Gordon, A. (2007). The validity and reliability of the Violence Risk Scale-Sexual Offender version: assessing sex offender risk and evaluating therapeutic change. Psychological assessment, 19(3), 318. doi. 10.1037/1040 3590.19.3.318

Petersilia, J., \& Turner, S. (1993). Evaluating Intensive Supervision Probation/Parole: Results of a Nationwide Experilllent.

Pithers, W. D., Kashima, K. M., Cumming, G. F., Beal, L. S., \& Buell, M. M. (1988). Relapse prevention of sexual aggression. Annals of the New York Academy of Sciences, 528(1), 244-260. doi. 10.1111/j.1749-6632.1988.tb50868.x

Proulx, J., McKibben, A., \& Lusignan, R. (1996). Relationships between affective components and sexual behaviors in sexual aggressors. Sexual Abuse: A Journal of Research and Treatment, 8(4), 279-289. doi.

Rettenberger, M., Matthes, A., Boer, D. P., \& Eher, R. (2010). Prospective Actuarial Risk Assessment A Comparison of Five Risk Assessment Instruments in Different Sexual 
Offender Subtypes. International Journal of Offender Therapy and Comparative Criminology, 54(2), 169-186. doi. 10.1177/0306624X08328755

Resnick, M. D. (2000). Protective factors, resiliency, and healthy youth development. Adolescent Medicine: State of the Art Reviews, 11(1), 157-164. doi.

Rice, M. E., \& Harris, G. T. (2005). Comparing effect sizes in follow-up studies: ROC Area, Cohen's d, and r. Law and human behavior, 29(5), 615. doi. 10.1007/s10979-005-6832-7

Rogers, R. (2000). The uncritical acceptance of risk assessment in forensic practice. Law and Human Behavior, 24(5), 595-605. 10.1023/A:1005575113507

Serin, R. (2007). The Dynamic Risk Assessment Scale for Offender Re-Entry (DRAOR). Unpublished scale. Carleton University, Ottawa, Ontario.

Serin, R. C., \& Mailloux, D. L. (2003). Assessment of Sex Offenders. Annals of the New York Academy of Sciences, 989(1), 185-197. 10.1111/j.1749-6632.2003.tb07305.x

Serin, R. C., Mailloux, D. L., \& Malcolm, P. B. (2001). Psychopathy, deviant sexual arousal, and recidivism among sexual offenders. Journal of Interpersonal Violence, 16(3), 234-246.

Serin, R.C. \& Prell, L. (2012). Pathways to crime desistance for probationers. Paper Presented at American Psychology-Law Society Annual Conference, March, San Juan, Puerto Rico.)

Seto, M. C., \& Fernandez, Y. M. (2011). Dynamic Risk Groups Among Adult Male Sexual Offenders. Sexual Abuse: A Journal of Research and Treatment, 23(4), 494-507.

Skeem, J. L., \& Monahan, J. (2011). Current directions in violence risk assessment. Current Directions in Psychological Science, 20(1), 38-42. 10.1177/0963721410397271

Tabachnick, B.G. and Fidell, L.S. (2007), Using Multivariate Statistics (5th ed.). New York: Allyn and Bacon.

Thornton, D. (2002). Constructing and testing a framework for dynamic risk assessment. Sexual Abuse: A Journal of Research and Treatment, 14(2), 139-153.

Ullrich, S., \& Coid, J. (2011). Protective factors for violence among released prisoners-Effects over time and interactions with static risk. Journal of consulting and clinical psychology, 79(3), 381. 10.1037/a0023613

Wakeling, H., Beech, A. R., \& Freemantle, N. (2013). Investigating treatment change and its relationship to recidivism in a sample of 3773 sex offendersin the UK. Psychology, Crime \& Law, 19(3), 233-252. 
YesBerg, J.A., Polaschek, D.L., \& Serin, R.C. (2013). Assessing dynamic risk and protective factors in the community: Examining the validity of the Dynamic Risk Assessment for Offender Re-entry. Unpublished Manuscript. 


\section{Appendix A: Dynamic Risk Assessment for Offender Re-Entry (DRAOR)}

(C) Ralph Serin, September 2007

\section{DYNAMIC RISK ASSESSMENT FOR OFFENDER RE-ENTRY (DRAOR)}

\begin{tabular}{|c|c|c|c|c|c|}
\hline \multirow{3}{*}{$\begin{array}{l}\text { Date: Name: } \\
\text { Offender reoffended/ } \\
\text { violated conditions? }\end{array}$} & \multicolumn{3}{|c|}{ PRN number: } & \multicolumn{2}{|c|}{ _Time on Supervision (mths) } \\
\hline & NO & \multirow[b]{2}{*}{ Breach } & \multirow[b]{2}{*}{ Recall } & \multirow[b]{2}{*}{ offence } & \multirow[b]{2}{*}{ Reimprisoned } \\
\hline & YES & & & & \\
\hline \multicolumn{6}{|c|}{ 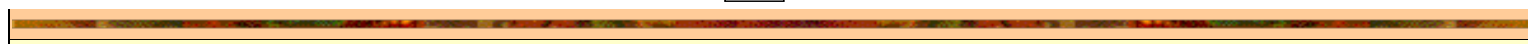 } \\
\hline \multicolumn{6}{|c|}{$\begin{array}{l}\text { STABLE RISK INDICATORS } \\
\text { Characteristics associated with risk and capable of changing over months or years. }\end{array}$} \\
\hline- & & 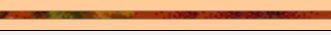 & & -5 & \\
\hline INDICATOR & \multicolumn{2}{|c|}{ SCORING CRITERIA } & \multicolumn{3}{|c|}{ SCORE (omit if unknown) } \\
\hline Peer Associations & \multicolumn{2}{|c|}{$\begin{array}{l}\text { Has only prosocial peers }(0)- \\
\text { Has only antisocial peers ( } 2)\end{array}$} & $\begin{array}{c}\mathbf{0} \\
\text { Not a } \\
\text { problem }\end{array}$ & $\begin{array}{c}1 \\
\begin{array}{c}\text { Slight/Possible } \\
\text { problem }\end{array}\end{array}$ & $\begin{array}{c}\mathbf{2} \\
\text { Definite } \\
\text { problem }\end{array}$ \\
\hline $\begin{array}{l}\text { Attitudes Towards } \\
\text { Authority }\end{array}$ & \multicolumn{2}{|c|}{$\begin{array}{l}\text { Prosocial attitudes }(0)- \\
\text { Antagonistic attitudes (2) }\end{array}$} & $\begin{array}{c}\mathbf{0} \\
\text { Not a } \\
\text { problem }\end{array}$ & $\begin{array}{c}1 \\
\begin{array}{c}\text { Slight/Possible } \\
\text { problem }\end{array}\end{array}$ & $\begin{array}{c}2 \\
\text { Definite } \\
\text { problem }\end{array}$ \\
\hline Impulse control & \multicolumn{2}{|c|}{$\begin{array}{l}\text { Autonomous/self monitoring }(0)- \\
\text { Highly impulsive }(2)\end{array}$} & $\begin{array}{c}\mathbf{0} \\
\text { Not a } \\
\text { problem }\end{array}$ & $\begin{array}{c}1 \\
\begin{array}{c}\text { Slight/Possible } \\
\text { problem }\end{array} \\
\end{array}$ & $\begin{array}{c}\mathbf{2} \\
\text { Definite } \\
\text { problem }\end{array}$ \\
\hline Problem-Solving & \multicolumn{2}{|c|}{$\begin{array}{l}\text { Ability to make good decisions }(0)- \\
\text { No consideration of consequences (2) }\end{array}$} & $\begin{array}{c}\mathbf{0} \\
\text { Not a } \\
\text { problem }\end{array}$ & $\begin{array}{c}\mathbf{1} \\
\begin{array}{c}\text { Slight/Possible } \\
\text { problem }\end{array}\end{array}$ & $\begin{array}{c}\mathbf{2} \\
\text { Definite } \\
\text { problem }\end{array}$ \\
\hline Sense of Entitlement & \multicolumn{2}{|c|}{$\begin{array}{l}\text { Recognition of their limitations (0) - } \\
\text { Inflated sense of self worth (2) }\end{array}$} & $\begin{array}{c}\mathbf{0} \\
\text { Not a } \\
\text { problem }\end{array}$ & $\begin{array}{c}1 \\
\begin{array}{c}\text { Slight/Possible } \\
\text { problem }\end{array} \\
\end{array}$ & $\begin{array}{c}\mathbf{2} \\
\text { Definite } \\
\text { problem }\end{array}$ \\
\hline Attachment with Others & \multicolumn{2}{|c|}{$\begin{array}{l}\text { Connected/concerned about others (0)- } \\
\text { Callous/indifferent towards others (2) }\end{array}$} & $\begin{array}{c}\mathbf{0} \\
\text { Not a } \\
\text { problem }\end{array}$ & $\begin{array}{c}1 \\
\begin{array}{c}\text { Slight/Possible } \\
\text { problem }\end{array} \\
\end{array}$ & $\begin{array}{c}\mathbf{2} \\
\text { Definite } \\
\text { problem }\end{array}$ \\
\hline & & & Total & 3LE Risk & / 12 \\
\hline
\end{tabular}

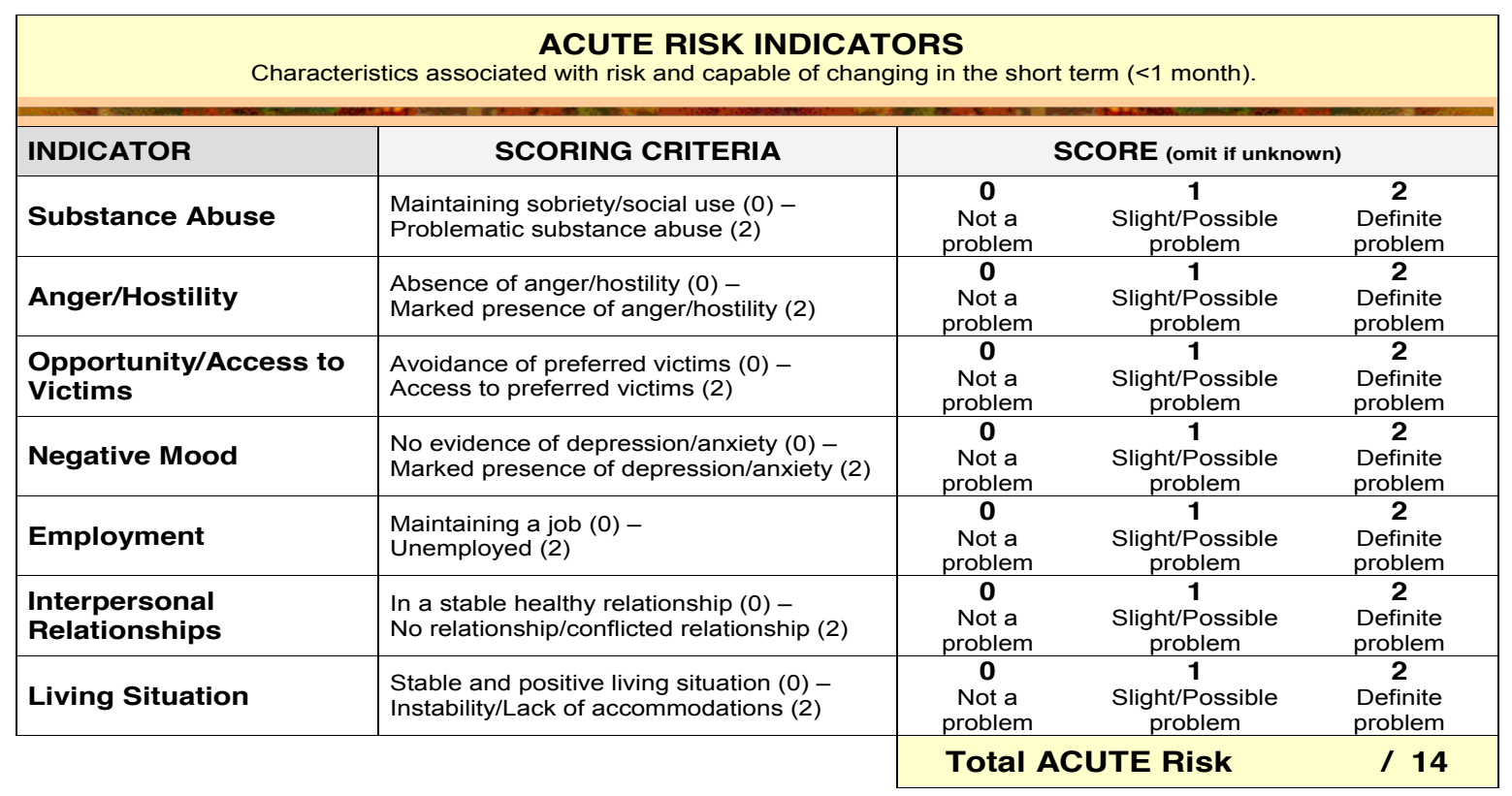




\begin{tabular}{|c|c|c|c|c|}
\hline \multicolumn{5}{|c|}{$\begin{array}{l}\text { PROTECTIVE FACTORS } \\
\text { Characteristics that may buffer risk. }\end{array}$} \\
\hline \multirow{2}{*}{$\begin{array}{l}\text { INDICATOR } \\
\text { Responsive to } \\
\text { Advice }\end{array}$} & \multirow{2}{*}{$\begin{array}{l}\text { SCORING CRITERIA } \\
\text { Follows direction from prosocial peers, } \\
\text { partners, supervisor, etc.. }\end{array}$} & \multicolumn{3}{|c|}{ SCORE (omit if unknown) } \\
\hline & & $\begin{array}{c}\mathbf{0} \\
\text { Not an } \\
\text { asset }\end{array}$ & $\begin{array}{c}\mathbf{1} \\
\begin{array}{c}\text { Slight/Possible } \\
\text { asset }\end{array}\end{array}$ & $\begin{array}{c}2 \\
\text { Definite } \\
\text { asset }\end{array}$ \\
\hline Prosocial Identity & $\begin{array}{l}\text { Legitimately views self as no longer criminally } \\
\text { oriented with behavioural examples. }\end{array}$ & $\begin{array}{c}\mathbf{0} \\
\text { Not an } \\
\text { asset }\end{array}$ & $\begin{array}{c}1 \\
\text { Slight/Possible } \\
\text { asset }\end{array}$ & $\begin{array}{c}\mathbf{2} \\
\text { Definite } \\
\text { asset }\end{array}$ \\
\hline $\begin{array}{l}\text { High } \\
\text { Expectations }\end{array}$ & $\begin{array}{l}\text { Individual, family, and/or community have high } \\
\text { expectations of success. }\end{array}$ & $\begin{array}{c}\mathbf{0} \\
\text { Not an } \\
\text { asset }\end{array}$ & $\begin{array}{c}\mathbf{1} \\
\begin{array}{c}\text { Slight/Possible } \\
\text { asset }\end{array}\end{array}$ & $\begin{array}{c}2 \\
\text { Definite } \\
\text { asset }\end{array}$ \\
\hline Costs/Benefits & $\begin{array}{l}\text { Evidence that rewards of prosocial behaviour } \\
\text { outweigh those of procriminal behaviour. }\end{array}$ & $\begin{array}{c}\mathbf{0} \\
\text { Not an } \\
\text { asset }\end{array}$ & $\begin{array}{c}\mathbf{1} \\
\begin{array}{c}\text { Slight/Possible } \\
\text { asset }\end{array} \\
\end{array}$ & $\begin{array}{c}\mathbf{2} \\
\text { Definite } \\
\text { asset }\end{array}$ \\
\hline Social Support & $\begin{array}{l}\text { Evidence that meaningful and accessible } \\
\text { prosocial supports exist. }\end{array}$ & $\begin{array}{c}\mathbf{0} \\
\text { Not an } \\
\text { asset }\end{array}$ & $\begin{array}{c}\mathbf{1} \\
\begin{array}{c}\text { Slight/Possible } \\
\text { asset }\end{array} \\
\end{array}$ & $\begin{array}{c}\mathbf{2} \\
\text { Definite } \\
\text { asset }\end{array}$ \\
\hline Social Control & $\begin{array}{l}\text { Conformity and compliance with prosocial } \\
\text { others; Strong internalized connection/bonds. }\end{array}$ & $\begin{array}{c}\mathbf{0} \\
\text { Not an } \\
\text { asset }\end{array}$ & $\begin{array}{c}1 \\
\begin{array}{c}\text { Slight/Possible } \\
\text { asset }\end{array} \\
\end{array}$ & $\begin{array}{c}2 \\
\text { Definite } \\
\text { asset }\end{array}$ \\
\hline & & \multicolumn{2}{|c|}{ Total PROTECTIVE } & / 12 \\
\hline
\end{tabular}

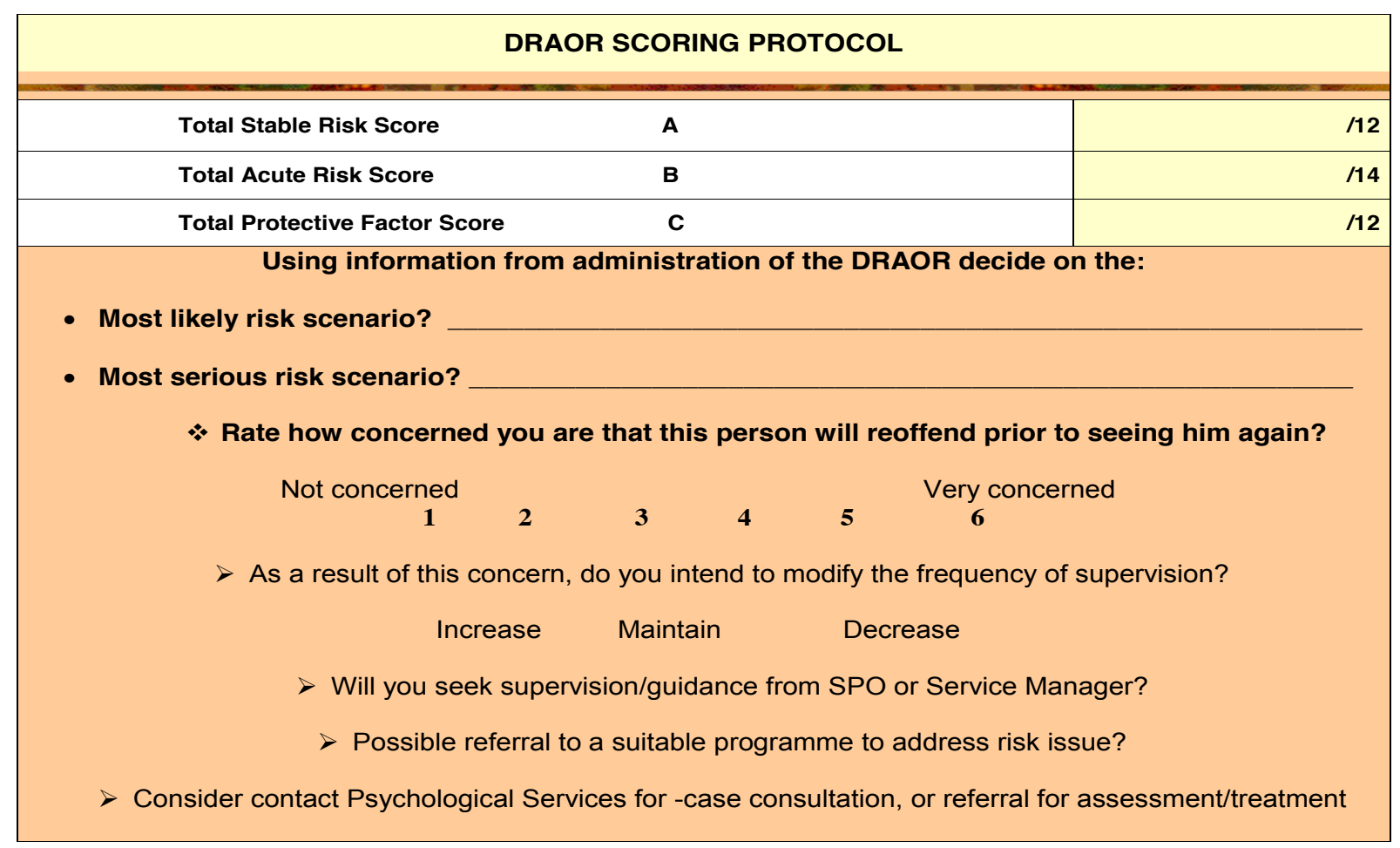




\begin{tabular}{|c|c|}
\hline \multicolumn{2}{|c|}{$\begin{array}{l}\text { NOTES } \\
\text { Identify any other factors that may be relevant for increasing OR decreasing risk }\end{array}$} \\
\hline ITEM & IMPACT on overall risk (circle) \\
\hline 1. & \\
\hline 2. & \\
\hline 3. & \\
\hline 4. & \\
\hline 5. & \\
\hline
\end{tabular}

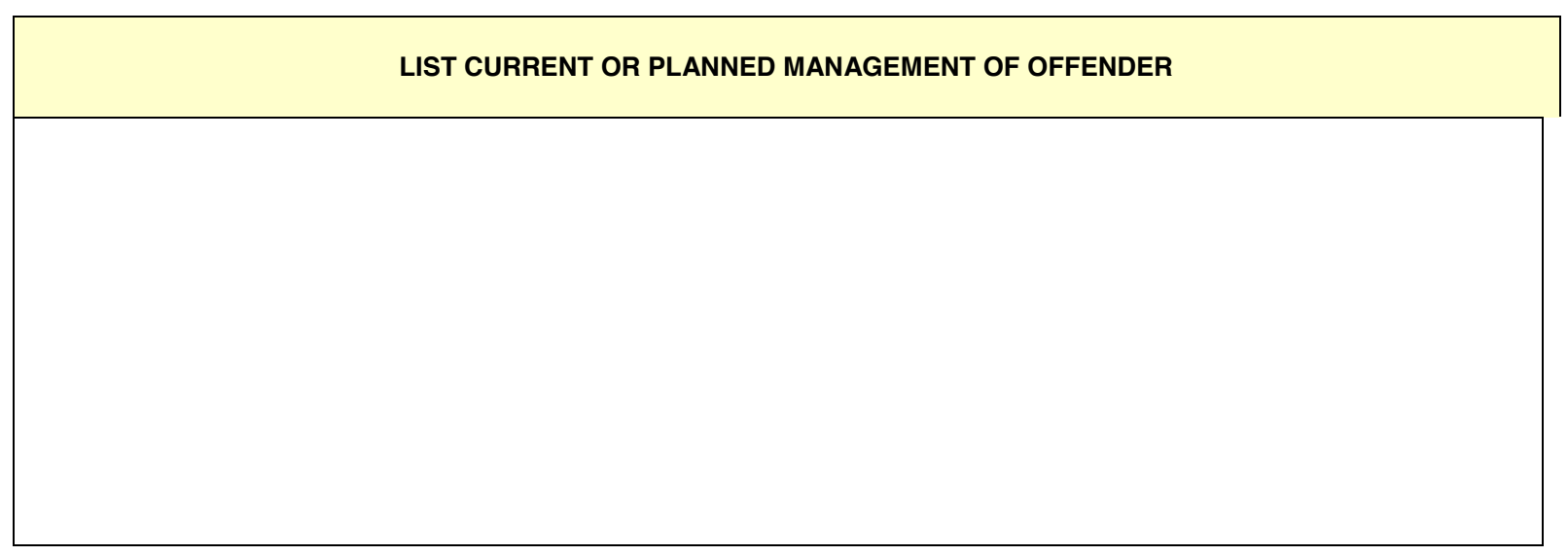




\section{Appendix B: Static-99R \\ Static-99R Coding Form}

\begin{tabular}{|c|c|c|c|c|}
\hline $\begin{array}{l}\text { Question } \\
\text { Number }\end{array}$ & Risk Factor & \multicolumn{2}{|c|}{ Codes } & Score \\
\hline 1 & Age at release & \multicolumn{2}{|c|}{$\begin{array}{l}\text { Aged } 18 \text { to } 34.9 \\
\text { Aged } 35 \text { to } 39.9 \\
\text { Aged } 40 \text { to } 59.9 \\
\text { Aged } 60 \text { or older }\end{array}$} & $\begin{array}{l}1 \\
0 \\
-1 \\
-3\end{array}$ \\
\hline 2 & Ever Lived With & \multicolumn{2}{|c|}{$\begin{array}{l}\text { Ever lived with lover for at least } \\
\text { two years? } \\
\text { Yes } \\
\text { No }\end{array}$} & $\begin{array}{l}0 \\
1\end{array}$ \\
\hline 3 & $\begin{array}{l}\text { Index non-sexual violence - } \\
\text { Any Convictions }\end{array}$ & \multicolumn{2}{|l|}{$\begin{array}{l}\text { No } \\
\text { Yes }\end{array}$} & $\begin{array}{l}0 \\
1\end{array}$ \\
\hline 4 & $\begin{array}{l}\text { Prior non-sexual violence - } \\
\text { Any Convictions }\end{array}$ & \multicolumn{2}{|l|}{$\begin{array}{l}\text { No } \\
\text { Yes }\end{array}$} & $\begin{array}{l}0 \\
1\end{array}$ \\
\hline 5 & Prior Sex Offences & $\begin{array}{l}\text { Charges } \\
0 \\
1,2 \\
3-5 \\
6+\end{array}$ & $\begin{array}{l}\text { Convictions } \\
0 \\
1 \\
2,3 \\
4+\end{array}$ & $\begin{array}{l}0 \\
1 \\
2 \\
3\end{array}$ \\
\hline 6 & $\begin{array}{l}\text { Prior sentencing dates } \\
\text { (excluding index) }\end{array}$ & \multicolumn{2}{|c|}{$\begin{array}{l}3 \text { or less } \\
4 \text { or more }\end{array}$} & $\begin{array}{l}0 \\
1\end{array}$ \\
\hline 7 & $\begin{array}{l}\text { Any convictions for non-contact sex } \\
\text { offences }\end{array}$ & \multicolumn{2}{|l|}{$\begin{array}{l}\text { No } \\
\text { Yes }\end{array}$} & $\begin{array}{l}0 \\
1\end{array}$ \\
\hline 8 & Any Unrelated Victims & \multicolumn{2}{|l|}{$\begin{array}{l}\text { No } \\
\text { Yes }\end{array}$} & $\begin{array}{l}0 \\
1\end{array}$ \\
\hline 9 & Any Stranger Victims & \multicolumn{2}{|l|}{$\begin{array}{l}\text { No } \\
\text { Yes }\end{array}$} & $\begin{array}{l}0 \\
1\end{array}$ \\
\hline 10 & Any Male Victims & \multicolumn{2}{|l|}{$\begin{array}{l}\text { No } \\
\text { Yes }\end{array}$} & $\begin{array}{l}0 \\
1\end{array}$ \\
\hline & Total Score & \multicolumn{2}{|c|}{$\begin{array}{l}\text { Add up scores from individual } \\
\text { risk factors }\end{array}$} & \\
\hline
\end{tabular}

\section{Translating Static-99R scores into risk categories}

\section{Score Label for Risk Category}

$\begin{array}{ll}-3 \text { through 1 } & =\text { Low } \\ 2,3 & =\text { Low-Moderate } \\ 4,5 & =\text { Moderate-High } \\ 6 \text { plus } & =\text { High }\end{array}$




\section{Appendix C: Stable-2007}

\section{STABLE-2007 Tally Sheet}

Subject Name:

Place of Scoring:

Date of Scoring: Name of Assessor:

\begin{tabular}{|l|l|l|}
\hline \multicolumn{1}{|c|}{ Scoring Item } & \multicolumn{1}{c|}{ Notes } & \multicolumn{1}{c|}{$\begin{array}{c}\text { Section } \\
\text { Total }\end{array}$} \\
\hline $\begin{array}{l}\text { Significant Social } \\
\text { Influences }\end{array}$ & \\
\hline $\begin{array}{l}\text { Capacity for } \\
\text { Relationship Stability }\end{array}$ & $\begin{array}{l}\text { (Only score this item for offenders with victims age 13 or } \\
\text { younger) }\end{array}$ & \\
\hline $\begin{array}{l}\text { Emotional ID with } \\
\text { Children }\end{array}$ & & \\
\hline Hostility toward women & & \\
\hline $\begin{array}{l}\text { General Social } \\
\text { Rejection }\end{array}$ & $\begin{array}{l}\text { Lack of concern for } \\
\text { others }\end{array}$ & \\
\hline $\begin{array}{l}\text { Impulsive } \\
\text { (Out of 24 for those without a child victim) }\end{array}$ & 26 \\
\hline $\begin{array}{l}\text { Poor Problem Solving } \\
\text { Skills }\end{array}$ & & \\
\hline $\begin{array}{l}\text { Negative Emotionality } \\
\text { Sex Drive }\end{array}$ & \\
\hline Sex Preoccupation & & \\
\hline Sex as Coping & & \\
\hline $\begin{array}{l}\text { Deviant Sexual } \\
\text { Preference }\end{array}$ & & \\
\hline $\begin{array}{l}\text { Deviant Sexual Interests in Possible Remission An offender who has scored a “2” based upon } \\
\text { historical facts can have their Deviant Sexual Interest score reduced by one point if the } \\
\text { following is present: The offender is involved in an age appropriate, consensual, satisfying } \\
\text { sexual relationship of at least one year's duration while "at risk" in the community with the } \\
\text { absence of behavioural indicators of Deviant Sexual Interest for 2 years. } \\
\text { If the presence of this relationship has been confirmed by a credible, independent, collateral } \\
\text { contact and the above condition applies you may enter and count a "negative 1" in this score } \\
\text { box - reducing the offender's overall score by "1" }\end{array}$ & \\
\hline $\begin{array}{l}\text { Co-operation with } \\
\text { Supervision }\end{array}$ & \\
\hline & & \\
\hline
\end{tabular}

Interpretive Ranges: $0-3=$ Low, $4-11=$ Moderate, $12+=$ High 
Appendix D: Acute-2007

ACUTE-2007 Tally Sheet

Subject Name:

Place of Scoring:

Date of Scoring:

Name of Assessor:

\begin{tabular}{|c|c|c|c|}
\hline $\begin{array}{l}\text { Sex/Violence Score } \\
\text { (Sum four factors) }\end{array}$ & Score & $\begin{array}{l}\text { General Recidivism Score } \\
\text { (Sum all seven factors) }\end{array}$ & Scoring \\
\hline - Victim Access & & \multirow{4}{*}{$\begin{array}{l}\rightarrow \rightarrow \text { Copy these scores over } \rightarrow \rightarrow \\
\rightarrow \rightarrow \text { Copy these scores over } \rightarrow \rightarrow \\
\rightarrow \rightarrow \text { Copy these scores over } \rightarrow \rightarrow\end{array}$} & \\
\hline - Hostility & & & \\
\hline - Sexual Pre-occupation & & & \\
\hline - Rejection of Supervision & & & \\
\hline & & - Emotional Collapse & \\
\hline & & $\begin{array}{l}\text { - } \quad \text { Collapse of } \\
\text { Social Supports }\end{array}$ & \\
\hline & & - Substance Abuse & \\
\hline $\begin{array}{r}\text { Sex/Violence Total } \\
\text { (Sum of four factors) }\end{array}$ & & $\begin{array}{l}\text { General Recidivism Risk Total } \\
\text { (Sum of all seven factors) }\end{array}$ & \\
\hline
\end{tabular}

$\underline{\text { Sex and Violence Risk and General Recidivism Risk }}$

Sex/Violence Nominal Categories

(Sum of four risk factors)

Low Priority

Moderate Priority

High Priority
General Recidivism Risk Nominal Categories (Sum of all seven risk factors)

Low Priority

Moderate Priority

0

High Priority

$1-2$

$3+$ (plus)

$2+$ (plus)

0 